\title{
Quantifying the benefits of entry into local phone service
}

\author{
Nicholas Economides* \\ Katja Seim** \\ and
}

V. Brian Viard***

Local telecommunications competition was an important goal of the 1996 Telecommunications Act. We evaluate the consumer welfare effects of entry into residential local telephone service in New York State using household-level data from September 1999 to March 2003. We address the prevalence of nonlinear tariffs by developing a discrete/continuous demand model that allows for service bundling and unobservable provider quality. We find that the average subscriber to the entrants' services gains a monthly equivalent of $\$ 2.33$, or $6.2 \%$ of her bill, in welfare from competition. These gains accrue primarily from firm differentiation and new plan introductions rather than from price effects.

\section{Introduction}

- Many countries, including Australia, Canada, the European Union's (EU) member countries, Japan, South Korea, and the United States, require incumbent telephone companies to allow entrants to lease individual elements of their network infrastructure at regulated rates, a practice commonly referred to as "unbundling." Regulators have imposed such requirements as a means to create competitive telecommunications markets by facilitating entry and thereby benefit consumers through adoption of new services. In this article, we study the consumer welfare implications of unbundling policies in the United States, using a household-level data set from New York State. Possible welfare effects, over the length of the time period of our study, derive from price reductions, development of new service offerings, and quality differences between the incumbent's and entrants' services.

\footnotetext{
*Stern School of Business, New York University; economides@stern.nyu.edu.

${ }^{* *}$ University of Pennsylvania; kseim@wharton.upenn.edu.

${ }^{* * *}$ Cheung Kong Graduate School of Business; brianviard@ckgsb.edu.cn.

We gratefully acknowledge the comments of Meghan Busse, Estelle Cantillon, Phillip Leslie, Eugenio Miravete, Amil Petrin, Peter Reiss, Marc Rysman, Alan Sorensen, Matt White, and participants at various conferences and seminars. We are also grateful for many helpful comments from two anonymous referees and the editor of this journal. We thank George David and Bill Goddard of the Center for Communications Management Information, a division of United Communications Group, for making the tariff data available. Steven Fan and Qingmin Liu provided excellent research assistance.
} 
In the United States, the markets for local residential and business telephone service were opened to competition following the 1996 Telecommunications Act (the 1996 Act). The 1996 Act allows three forms of entry: replication of the incumbent's infrastructure, lease of the incumbent's existing infrastructure (unbundling), or resale of the incumbent's services. By the late 1990s, competitive local exchange carriers had begun service in most U.S. states, primarily through leasing unbundled infrastructure or reselling service. As of December 31, 2003, entrants leased $60.6 \%$ of their residential and business lines and another $16.0 \%$ involved the resale of an incumbent's services (Federal Communications Commission, 2004).

We evaluate the consumer welfare effects of entry in New York State by quantifying the effects based on actual consumer choices. Although there are a few other estimates of the expected savings by U.S. consumers because of entry into local phone service (see Telecommunications Research \& Action Center, 2000, 2001), these rely on hypothetical consumer migrations and ignore geographic differences in providers' service offerings. Instead, the household-level data that we utilize allow us to model geographic variations in service offerings as well as individual choice behavior using detailed demographics, thereby permitting a distinction between welfare effects generated by lower prices, increased product variety, and firm-level differentiation.

Providers sell residential local phone service under a menu of two- or three-part tariffs with monthly fees and per-unit prices, allowing consumers to choose their plan and their usage. Such mixed discrete/continuous choices also occur in other markets such as energy, information, and Internet access. Hanemann (1984) provides a methodology for estimating econometric models that link the discrete and continuous choices in the same utility maximization problem. We expand his framework along several dimensions. Our utility specification allows for flat-rate plans at zero marginal prices, bundling of multiple services under one plan, unobserved vertical quality differences across firms, and horizontal firm differentiation. We employ a maximum likelihood estimation technique that combines the information from the discrete and continuous choices by consumers. Our analysis focuses only on the demand effects of entry because regulation of incumbent prices for both the shared infrastructure and the final services effectively limits the role of supply-side responses.

We estimate our model using data from a random sample of New York households over a three and a half year period beginning in late 1999. We focus on New York because it was one of the first states to experience entry under the 1996 Act. Significant entry occurs by the end of our sample period, with entrants serving over $20 \%$ of the access lines. The largest entrants are AT\&T and MCI, which comprise approximately $85 \%$ of the residential lines served by entrants. They compete with the incumbent, Verizon, whose customers are also included in the analysis.

Applying our econometric model to the household-level data, we are able to quantify the full distribution of welfare effects of entry. We find that these effects differ dramatically across households, underscoring the need for a household-level analysis. The addition of the entrants' plans to the choice set leads, on average, to household gains of $\$ 0.83$ per month, or $2.5 \%$ of households' average monthly bill. The standard deviation of welfare gains across households is $\$ 3.42$, with average gains of $\$ 2.77$ and $\$ 1.13$ accruing to AT\&T and MCI subscribers, respectively.

Exploiting the detailed household-level data, we decompose the different sources of consumer benefits from entry and determine who gains the most from unbundling. The entrants introduce several new plans not offered by the incumbent. We find that considerable gains to consumers result from these new plan varieties. The introduction by AT\&T and MCI of a flat-rate plan previously unavailable in New York City entails a welfare increase of $\$ 0.68$ per month on average, whereas AT\&T's introduction of a combined local and regional calling plan results in a welfare increase of $\$ 0.21$ per month on average across all households.

Although the entrants employ the same technological infrastructure as the incumbent, their services are vertically and horizontally differentiated due to nontechnological factors, such as customer support and marketing. Observed and unobserved firm effects play an important role in households' choices. Prior experience with an entrant's long-distance services is particularly important, suggesting that households consider a prior relationship in forming their assessment of 
the entrant's local service quality. We find that AT\&T households enjoy monthly benefits of $\$ 1.84$ per month from such differentiation, whereas MCI households receive monthly benefits of $\$ 0.64$. This compares to savings of $\$ 1.15$ and $\$ 0.40$ over what the average AT\&T and MCI household, respectively, would have paid on Verizon based on pure price effects alone. Thus, a focus only on prices, disregarding firm differentiation, significantly understates household welfare gains.

Relating household-level welfare benefits to household characteristics, we find that larger households in New York City benefit more from entry, presumably due to the entrants' introductions of new flat-rate plans there. The fact that high-usage households, which on average are lower income, black, and larger, gain more than other households do suggests that competition intensifies primarily for high-valuation customers. Customers of the entrants' long-distance services also gain more, consistent with the importance of horizontal firm differentiation.

Our results are particularly interesting because, according to the provisions of the 1996 Act, incumbents and entrants were to compete starting with identical inputs and on an equal footing. Our finding that entrants offer differentiated services and introduce meaningful new plan types is thus important for quantifying the benefits of regulatory measures to increase competition when entrants and incumbents share infrastructure. We find that these effects are more important than the pure price effects. This is consistent with results in Greenstein and Mazzeo (2006), who find that entrants' initial market selection depends on differentiation strategies, in addition to factors highlighted by Crandall and Sidak (2002) and Zolnierek, Eisner, and Burton (2001), such as demand and cost differences across markets, economies of geographic scope, and regulatory stringency.

In March 2004, the DC Court of Appeals reversed the Federal Communications Commission's (FCC) implementation of unbundling policies, finding that the absence of nationwide access to the local telecommunications network at "cost plus reasonable profit" did not "impair" entrants, as the 1996 Act required. Thereafter, incumbents were not required to follow cost-based pricing in leasing the local network. As a result, the largest entrants stopped accepting new customers (see Economides, 2005 for more detail). Despite the short-lived effects of unbundling in the United States, the experience through 2004 is instructive for several reasons. First, it offers a unique opportunity to inform decisions of whether to initiate or continue unbundling policies in local telecommunications markets in other countries or settings. These include unbundling cable modem Internet access, presently awaiting implementation in Canada, cable television service, under consideration in The Netherlands, and DSL Internet access, mandated by the EU's 2000 Unbundling Regulation. Second, the detailed U.S. data available allow an assessment of the economic implications of unbundling policies, such as the sources and magnitudes of any welfare gains and the types of households that are likely to benefit. Although the specifics of settings differ, our results suggest that initiatives to promote unbundled access in other countries should consider broader implications beyond price effects.

\section{New York's local telephone markets}

- New York has two sizeable incumbents, whose geographic territories are displayed in Figure 1. Frontier Communications of New York controls $8 \%$ of incumbent business and residential access lines as of December 31, 2001, while Verizon controls 89\%. The 1996 Act introduces local telecommunications competition in Verizon's region, which had not previously opened its markets to competition.

The New York Public Service Commission (NYPSC) serves two roles related to our study in regulating the local phone market. First, it sets infrastructure lease rates that entrants pay to the incumbent. These rates remain stable during our sample period with the exception of a decrease of about $30 \%$ in July 2002 . The lease rates vary by geographic zone within the state, averaging approximately $\$ 20$ per line served as of early 2001 and falling to approximately $\$ 15$ by the middle 


\section{FIGURE 1}

INCUMBENT LOCAL EXCHANGE CARRIERS, NEW YORK STATE

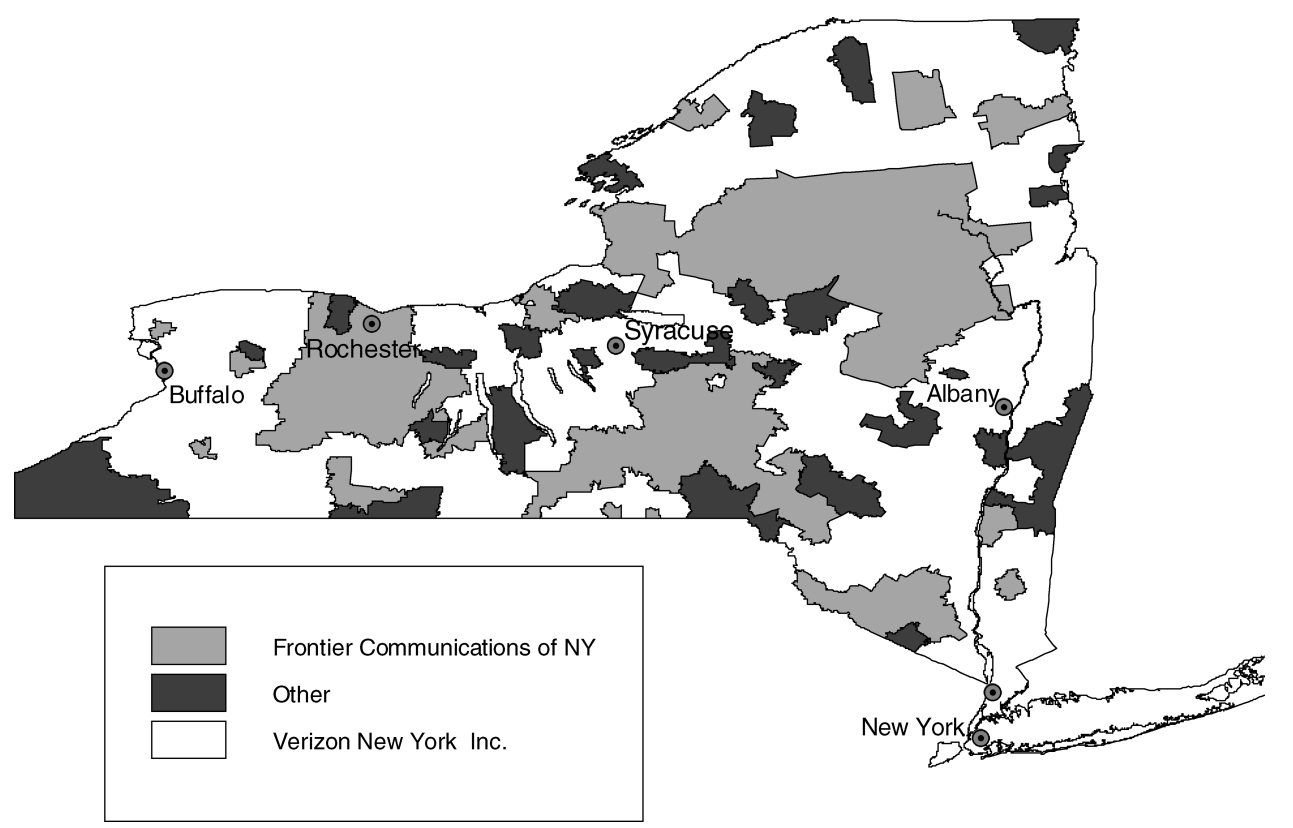

of 2002. ${ }^{1}$ Second, the NYPSC regulates the retail rates that incumbents charge for local phone services. We describe the retail prices faced by customers in our sample in Section 3.

The entrants' market share of residential lines increases steadily from $6 \%$ in 1999 to $22 \%$ in 2002. The main entrants in New York during our sample period are AT\&T and MCI, both of which expand into local service from the long-distance market. As of December 31, 2001, AT\&T and MCI hold shares of 58\% and 27\%, respectively, of residential lines served by entrants in New York. AT\&T's initial entry into New York occurs in late 1999 and focuses on the state's metropolitan areas, as displayed in Figure 2. In 2001, AT\&T enters into the remainder of Verizon's territory. MCI enters Verizon's entire territory in 1999.

By 2001, each of the three carriers offers three types of phone service: local, regional, and long-distance. Local service applies to phone calls in the household's local calling area. The carriers define local calling areas identically. These differ significantly in the population served, ranging from 1,873 people in Indian Lake to 7.98 million people in New York City, with an average of 304,597 people. Local calling areas are grouped into seven regional calling areas. The local service provider generally handles calls within these regions and outside of the household's local calling area, but imposes higher prices. All remaining calls qualify as long-distance calls. Although Verizon also began offering long-distance service in 2001, it and the entrants provided long-distance service primarily under separate calling plans from local and regional service during our sample period. As a result, we concentrate on estimating the benefits from competition in local and regional service.

The carriers provide local and regional phone services through monthly calling plans, of which three types are available to New York customers. Metered plans include a monthly fee to obtain service and a per-call fee for usage. Flat-rate plans specify a monthly fee for unlimited calling. Hybrid plans are three-part tariffs where a household pays a monthly fee to obtain a certain number of calls at zero marginal price. For calls above the predefined allowance, the household

\footnotetext{
${ }^{1}$ Based on Appendices 2 and 3 in cad.state.wv.us/Intro\%20to\%20Matrix\%201-02.htm. The cost figures assume 1000 minutes of usage per month and incorporate discounts for leasing all network elements.
} 
FIGURE 2

AT\&T'S ENTRY INTO LOCAL SERVICE, NEW YORK STATE, 1999

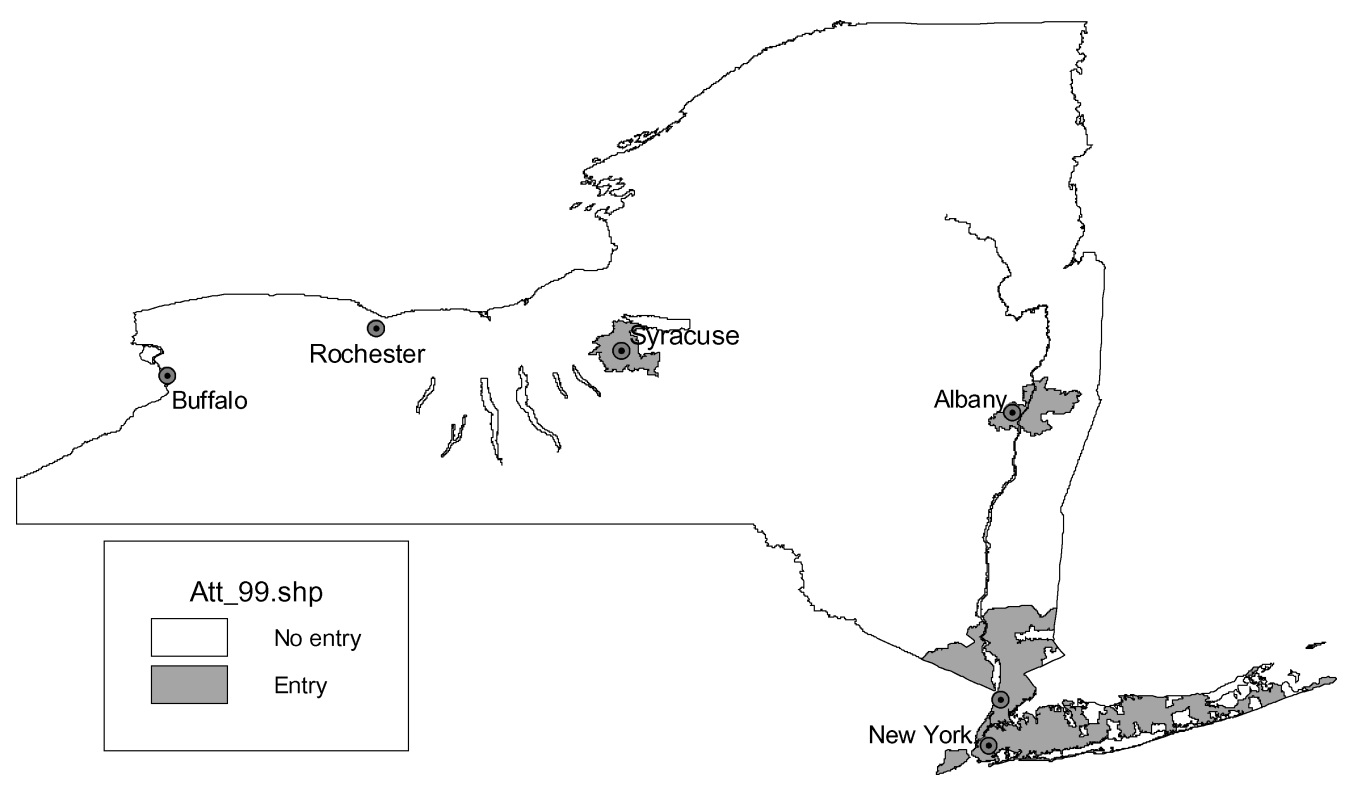

pays a positive marginal price. The FCC requires local carriers to offer additional calling plans at reduced rates to qualifying low-income households.

Local phone service providers also offer add-on features, such as call waiting, call forwarding, three-way calling, and speed dialing, to their customers. During the time period of our study, the carriers do not bundle these features with local or regional service. Instead, they offer them as optional features that households purchase along with basic service.

\section{Data}

- We analyze plan choice and usage behavior using data on a sample of New York households collected by TNS Telecoms (TNS), complemented with data on the geography and structure of local telephone markets from various sources. TNS's Bill Harvesting data contain survey data from residential customers. TNS gathers demographic information on the households and asks them to submit their actual phone bill. Because willingness to respond varies by household characteristics, TNS employs oversampling to obtain a random sample. Most households participate in the survey only once. Our sample runs from September 1999 through March 2003 and covers a total of 7222 cross-sectional household observations.

For each household, the data set contains information on its local carrier choice and any detailed line items recorded on its local telephone bill, including the services the household purchased, total amount paid, and a breakdown of the bill into services, fees, and regulatory charges. For households that subscribe to metered service or exceed their call allowance on a hybrid plan, we observe the number of calls made during the billing period. Local usage is generally not available for the remaining households, notably those on flat-rate plans.

The TNS data do not directly identify the calling plan chosen by the household. Instead, we use descriptions of purchased services and associated expenditures to identify the household's chosen calling plan based on publicly available information. The NYPSC requires all carriers to publicly file retail price information whenever prices change, allowing us to construct the universe of calling plans and their prices at all times during our sample period. Because providers adjust consumers' bills to reflect price changes as they go into effect, we identify each household's plan 
TABLE 1 Descriptive Statistics-Demographic Variables

\begin{tabular}{|c|c|c|c|c|c|c|}
\hline Variable & Mean & $\begin{array}{l}\text { Standard } \\
\text { Deviation }\end{array}$ & Minimum & Maximum & Obs & Description \\
\hline CELLULAR & 0.360 & 0.480 & 0 & 1 & 5496 & At least one cellular phone in household \\
\hline INTERNET & 0.411 & 0.492 & 0 & 1 & 5524 & Internet access at home \\
\hline HHSIZE & 2.083 & 1.190 & 1 & 5 & 5524 & Number of people in hh \\
\hline INCOME & 3.894 & 3.385 & 0.425 & 12.86 & 5524 & Monthly hh income $(000)$ \\
\hline AGE (15-34) & 0.110 & 0.313 & 0 & 1 & 5524 & Head of hh between 15 and 34 years old \\
\hline AGE (35-54) & 0.353 & 0.478 & 0 & 1 & 5524 & Head of hh between 35 and 54 years old \\
\hline $\operatorname{AGE}(55+)$ & 0.536 & 0.499 & 0 & 1 & 5524 & Head of hh above 54 years old \\
\hline BLACK & 0.058 & 0.234 & 0 & 1 & 5524 & Head of hh is black \\
\hline HISPANIC & 0.048 & 0.214 & 0 & 1 & 5524 & Head of hh is Hispanic \\
\hline RACEO & 0.049 & 0.215 & 0 & 1 & 5524 & Head of hh is not white or black \\
\hline MOVED1Y & 0.055 & 0.228 & 0 & 1 & 4556 & Hh moved within last year \\
\hline NYCITY & 0.153 & 0.360 & 0 & 1 & 5524 & Hh lives in New York City \\
\hline SAMLD & 0.388 & 0.487 & 0 & 1 & 5524 & Hh has same local and long-distance carrier \\
\hline AT\&T & 0.885 & 0.319 & 0 & 1 & 592 & \\
\hline MCI & 0.853 & 0.355 & 0 & 1 & 218 & \\
\hline VERIZON & 0.306 & 0.461 & 0 & 1 & 3975 & \\
\hline SAMBILL & 0.801 & 0.400 & 0 & 1 & 3825 & Hh billed jointly for local and long distance \\
\hline AT\&T & 0.970 & 0.170 & 0 & 1 & 504 & \\
\hline MCI & 0.944 & 0.231 & 0 & 1 & 195 & \\
\hline VERIZON & 0.763 & 0.425 & 0 & 1 & 2541 & \\
\hline
\end{tabular}

among contemporaneous plans. Across providers, we are able to match $97.2 \%$ of households to a calling plan.

Because AT\&T and MCI did not enter into Frontier Communications's territory, we focus on households that reside in Verizon's territory. We use the household's location, available at the zip-code level, together with detailed data on the availability of AT\&T's and MCI's local service, to construct the household's choice set of local service carriers and plans at the time of its bill. We employ the Center for Communications Management Information's QTEL Local Calling Area Database, which maps the first six digits of a telephone number to the set of telephone numbers that can be called locally, to identify each household's local calling area based on its telephone number. To measure the size of the potential calling area for local and regional service, the "coverage area," we use mapping software to measure the calling area's population based on the 2000 Census.

Of the 7222 households in the data, 696 subscribe to AT\&T, 931 to Frontier Communications, 362 to MCI, and 5233 to Verizon. We exclude the Frontier customers and the remaining 547 subscribers to other, small carriers from the sample. The entrants' representation in the resulting sample is similar to aggregate market shares for New York. In 2001, for example, the NYPSC reports market shares based on number of lines of $11.8 \%$ and $5.6 \%$ for AT\&T and MCI, respectively, while in the TNS sample for the same year, $12.2 \%$ of households are AT\&T customers and 5.4\% are MCI customers. Due to missing information, reporting errors by TNS, or other data issues, we are not able to use all available observations in our estimation. The sample observations with complete demographic and usage information total 592 (85\%) for AT\&T, 218 (62\%) for MCI, and 3981 (76\%) for Verizon. ${ }^{2}$

The TNS data contain information on the household's basic demographic profile as well as use of other telecommunications services and technology products. We summarize the available variables in Table 1. Household size and income are likely the strongest proxies for demand for usage. TNS reports the household's income as a categorical variable. To transform it into a single

\footnotetext{
${ }^{2}$ Excluding households that switch or connect service during the month, have multiple phone lines, or subscribe to plans unavailable to the population at large or bundle long-distance and local service results in 601 AT\&T, $218 \mathrm{MCI}$, and 5021 Verizon households. The remaining decrease in observations is due to incomplete demographic data.
} 
continuous variable, we assign to each household an income equal to the predicted average income level in its category, as in Miravete (2002b). Compared to the state's aggregate distribution, the income distribution is slightly skewed toward lower-income households. Other demand shifters include whether the household moved in the past year and had to choose a new service provider, whether at least one member of the household subscribes to cellular service, and whether the household has access to the Internet at home.

Table 1 displays the households' long-distance provider choices in relation to their local provider choices. Across all firms, 38.8\% of households use the same provider for local and long-distance service. This fraction is significantly higher for entrants, however; $88.5 \%$ of AT\&T customers and $85.3 \%$ of MCI customers subscribe to these providers' long-distance services. In the data, we also observe whether households receive a single bill for local and long-distance service. Verizon offers households an option to request that their long-distance service be billed through the incumbent on a single bill regardless of long-distance provider. Of the households that use Verizon's local service, $76.3 \%$ elect this co-billing option. The entrants offer a similar service for a charge of $\$ 1.50$ per month. Of AT\&T and MCI's customers, $97.0 \%$ and $94.4 \%$, respectively, receive the same bill, either because they use the same firm's long-distance service or pay the $\$ 1.50$ charge.

Some simplifications of the data are necessary to make estimation tractable. Depending on the chosen plan, carriers bill usage in terms of either minutes or calls. They generally bill regional calling on a per-call basis. Charges may vary by time of day, length of call, or, in the case of regional service, distance of call. We convert all usage information to a per-call basis, using the empirical distributions of call lengths, intra-day calling patterns, and call distances to construct measures of numbers of calls and weighted-average per-call prices. In the remainder of the article, we ignore within-call nonlinear pricing due to the household's choice of timing of individual calls or distance of calls made. The latter could bias our results if, for example, a customer's preference for making many short calls steers her to a provider that bills on a per-minute rather than a per-call basis. Descriptively, however, the data do not suggest that households' call durations or their call distributions over the course of the day differ significantly across carriers, providing some evidence that the role of within-call nonlinear pricing in driving households' plan choices is limited.

Typically, the carriers each offer one metered plan and one flat-rate plan for local calls. There are several exceptions to this. From 1999 until September 2000, MCI offers an additional hybrid plan for local service. Only AT\&T offers flat-rate service to New York City customers during the entire sample period, while MCI introduces this option in September 2000 and Verizon does so only after the end of our sample period. In addition, AT\&T offers a calling plan that bundles local and regional services into a hybrid plan with a single price for both local and regional calls in excess of the joint call allowance. On average, households have a choice of six calling plans across providers, ranging from three plans in areas where AT\&T entered only in 2001 to eight in areas where all three firms operate.

Under the NYPSC's regulation, Verizon holds basic service prices constant from at least September 1, 1995 until September 2000 and reduces them thereafter. Verizon thus does not change its pricing as an entry-deterrence strategy. In parallel with the 2002 decrease in wholesale lease rates, the NYPSC grants Verizon a retail rate increase. Verizon's prices for local metered and regional service differ for metro and non-metro regions, and prices for flat-rate service differ across five geographic areas. AT\&T and MCI employ a simpler pricing strategy, charging a single price to all metered customers and differentiating pricing of the flat-rate plan only between metro and non-metro regions.

Table 2 summarizes the plan choices and prices paid by households in the sample. A large share of customers, $47.5 \%$, subscribe to metered service, which reflects in part that in New York City, this is frequently the only type of service offered. Verizon's metered service on average dominates its competitors' offerings on price: the average fixed fee paid by Verizon households is only $\$ 5.99$, compared to $\$ 8.21$ and $\$ 6.27$ for AT\&T and MCI, respectively, while Verizon's average 
TABLE 2 Household Carrier and Plan Choices, Usage, and Prices Paid

\begin{tabular}{|c|c|c|c|c|c|c|}
\hline & & Mean & Standard Deviation & Minimum & Maximum & Obs \\
\hline \multicolumn{7}{|c|}{ Local carrier choices } \\
\hline \multicolumn{2}{|l|}{ AT\&T } & 0.090 & 0.286 & 0 & 1 & 7769 \\
\hline \multicolumn{2}{|l|}{ Frontier } & 0.120 & 0.325 & 0 & 1 & 7769 \\
\hline \multicolumn{2}{|l|}{ MCI } & 0.047 & 0.211 & 0 & 1 & 7769 \\
\hline \multicolumn{2}{|l|}{ Verizon } & 0.674 & 0.469 & 0 & 1 & 7769 \\
\hline \multicolumn{2}{|l|}{ Other } & 0.070 & 0.256 & 0 & 1 & 7769 \\
\hline \multicolumn{7}{|c|}{ Plan choices } \\
\hline \multicolumn{2}{|c|}{ Flat-rate plan } & 0.415 & 0.493 & 0 & 1 & 5524 \\
\hline \multicolumn{2}{|c|}{ Metered plan } & 0.475 & 0.499 & 0 & 1 & 5524 \\
\hline \multicolumn{2}{|c|}{ Other plan ${ }^{\mathrm{a}}$} & 0.109 & 0.312 & 0 & 1 & 5524 \\
\hline \multicolumn{7}{|c|}{ Usage of local service (\# of calls) } \\
\hline \multicolumn{2}{|c|}{ Overall } & 89.867 & 105.853 & 1 & 1299 & 2928 \\
\hline \multicolumn{2}{|c|}{ Metered plans } & 89.164 & 94.855 & 1 & 857 & 2623 \\
\hline \multicolumn{2}{|c|}{ Other plan types } & 95.908 & 173.894 & 1 & 1299 & 305 \\
\hline \multicolumn{7}{|c|}{ Usage of regional service (\# of calls) } \\
\hline \multicolumn{2}{|c|}{$\%$ of households, usage $=0$} & 0.655 & 0.475 & 0 & 1 & 5405 \\
\hline \multicolumn{2}{|c|}{ Overall } & 5.052 & 15.557 & 0 & 257 & 5405 \\
\hline \multicolumn{2}{|c|}{ Households with usage $>0$} & 14.648 & 23.694 & 1 & 257 & 1864 \\
\hline \multicolumn{7}{|c|}{ Local usage prices per call } \\
\hline \multicolumn{2}{|c|}{ AT\&T } & 0.107 & 0.015 & 0.090 & 0.120 & 42 \\
\hline \multicolumn{2}{|l|}{ MCI } & 0.100 & 0.000 & 0.100 & 0.100 & 48 \\
\hline \multicolumn{2}{|c|}{ Verizon } & 0.091 & 0.011 & 0.084 & 0.109 & 2506 \\
\hline \multicolumn{7}{|c|}{ Regional usage prices per call } \\
\hline \multicolumn{2}{|c|}{$\mathrm{AT} \& \mathrm{~T}$} & 0.299 & 0.048 & 0.270 & 0.379 & 469 \\
\hline \multicolumn{2}{|l|}{ MCI } & 0.677 & 0.000 & 0.677 & 0.677 & 218 \\
\hline \multicolumn{2}{|l|}{ Verizon } & 0.351 & 0.061 & 0.270 & 0.429 & 3981 \\
\hline \multicolumn{7}{|c|}{ Monthly fixed fees } \\
\hline \multirow[t]{2}{*}{ AT\&T } & Metered plans & 8.214 & 1.503 & 6.500 & 9.500 & 42 \\
\hline & Other plan types & 21.757 & 2.752 & 15.350 & 27.950 & 550 \\
\hline \multirow[t]{2}{*}{ MCI } & Metered plans & 6.270 & 0.000 & 6.270 & 6.270 & 48 \\
\hline & Other plan types & 18.344 & 2.688 & 14.990 & 21.990 & 170 \\
\hline Verizon & Metered plans & 5.985 & 2.091 & 1.000 & 8.610 & 2506 \\
\hline & Other plan types & 16.362 & 3.115 & 7.850 & 21.520 & 1475 \\
\hline
\end{tabular}

${ }^{a}$ Other plans include hybrid plans and the bundled local and regional service plan.

per-call charges are below its competitors' prices by approximately $\$ 0.01$. Similarly, Verizon's flat-rate customers pay lower fixed fees on average than their AT\&T and MCI counterparts. Due to varying choice sets across households and additional charges beyond basic service charges, these statistics do not imply necessarily that Verizon is the lowest-cost option for all households in its territory. Nevertheless, they raise the question of which considerations apart from price drive a household's carrier choice, which we investigate in Section 4.

\section{Consumer response to entry}

- A usual difficulty in assessing the effect of entry is controlling for the incumbent's response. In our setting, we take advantage of the fact that the NYPSC regulates the incumbent's prices for services and infrastructure leases and its service quality. ${ }^{3}$ Because the entrants primarily lease the incumbent's infrastructure, the industry's overall cost structure remains relatively unchanged over

\footnotetext{
${ }^{3}$ The NYPSC requires Verizon to tabulate eight service quality measures on a monthly basis, including customer trouble report rate, out of service rate, and repair and installation times. Failing to meet service quality standards results in penalties.
} 
the time period we analyze, aside from potentially increased marketing expenditures and cost of services such as operators.

Although entry entails changes in and a reallocation of industry profit, we focus on demandside responses to changes in the carrier set, instead of conducting a full welfare analysis of entry. We consider several possible effects of entry on consumer welfare, including pure price effects (holding usage quantity and service quality constant) and horizontal and vertical differentiation effects resulting from the increased number of provider or plan choices.

Even though bundling of local and long-distance services in a single plan is rare during our sample, we recognize two ways in which the household's long-distance carrier choice is relevant to consumer welfare. First, the entrants offer discounts to households that choose them for both services. This discount is $\$ 1.00$ for AT\&T during the entire sample period and $\$ 4.95$ for MCI from August 1999 to August 2000. We account for these discounts in our estimation of the price effects. Second, households may place value on receiving a single telecommunications bill for both services, providing an additional incentive to choose the same local and long-distance provider.

We begin with an assessment of the pure price effects from entry by computing the cost savings that households realize from the choice of an entrant's service over the incumbent's offerings, holding household usage constant. We then turn to the role that non-price effects play in the demand for local service, as a motivation for the econometric model discussed in Section 5.

$\square \quad$ Monetary effects of entry. Abstracting from usage responses and quality differences among firms, we compute the effect of entry by simply determining how much consumers in the Verizon region save from the presence of the entrants. We evaluate the amount of money that AT\&T or MCI local service customers would pay to Verizon in the absence of the entrants' services. This requires mapping the household to a specific Verizon plan based on its usage and evaluating the amount it would pay to Verizon under that plan, relative to its actual payment to one of the entrants.

We make several assumptions in this counterfactual. Because we do not observe how long a household has been with a carrier, our comparisons are contemporaneous. For example, for a household that uses AT\&T in January 2001, the hypothetical choice set includes Verizon plans available at that same time. We assume further that households choose the optimal plan, both among the entrants' offerings and in the counterfactual among Verizon's offerings. We discuss the validity of this assumption below. If a household chooses an entrant's flat-rate service, we compare its expenditure with that on a flat-rate plan from Verizon, if available, because we generally do not observe usage for such households. If Verizon flat-rate service is not available, for example in New York City, we base charges on the household's estimated usage conditional on its usage exceeding the break-even point between the entrants' metered and flat-rate services. ${ }^{4}$ Of these assumptions, only the assumption of optimal plan choice carries through to the remainder of the article.

Table 3 presents the results of the counterfactual with savings divided by source. On average for the same usage, AT\&T customers pay $\$ 1.15$ per month less than on Verizon's optimal contemporaneous plan. Of this, $\$ 0.89$ on average is due to buying both long-distance and local service from AT\&T, representing the $89 \%$ of AT\&T sample households that receive the $\$ 1.00$ long-distance discount. Another $\$ 0.53$ arises from savings on add-on features. As suggested by the price patterns in Table 2, households on average lose money on charges for local and regional service by using AT\&T.

The results for MCI are similar, although households save less on average. The mean household saves $\$ 0.40$ per month on its bill relative to subscribing to Verizon's optimal

\footnotetext{
${ }^{4}$ A second instance where Verizon's offerings do not match the entrants' offerings arises for AT\&T's bundled local and regional service. In this case, we assume that the households would choose Verizon's flat-rate plan for local usage and estimate regional charges based on average regional usage for the sample.
} 
TABLE 3 Monthly Average Savings of Entrants' Customers $(N=592$ for AT\&T, $N=218$ for MCI)

\begin{tabular}{llcrr}
\hline \multirow{2}{*}{ Carrier } & \multicolumn{1}{c}{ Category } & Charge & $\begin{array}{c}\text { Savings over } \\
\text { Verizon }\end{array}$ & $\begin{array}{c}\text { Percentage } \\
\text { Savings }^{\mathrm{a}}\end{array}$ \\
\hline \multirow{2}{*}{ AT\&T } & \multicolumn{1}{c}{$\begin{array}{c}\text { Local and regional usage charges } \\
\text { Add-on features charges }\end{array}$} & $\$ 23.25$ & $-\$ 0.26$ & -1.0 \\
& Buying long-distance from AT\&T & 3.18 & 0.53 & 2.0 \\
& Total savings & & 0.89 & 3.3 \\
& Standard error, savings & & 1.15 & 4.3 \\
\multirow{3}{*}{ MCI } & Local and regional usage charges & $\$ 19.65$ & $-\$ 0.61$ & -2.9 \\
& Add-on features charges & 2.00 & -0.06 & -0.3 \\
& Buying long-distance from MCI & & 1.07 & 5.1 \\
& Total savings & & 0.40 & 1.9 \\
\hline
\end{tabular}

${ }^{a}$ As percentage of average total Verizon charges ( $\$ 26.69$ for AT\&T analysis, \$20.98 for MCI analysis).

contemporaneous plan. The average household loses money on combined local and regional charges as well as on add-on features. Households benefit on average by $\$ 1.07$ from discounts for subscribing to both local and long-distance service from MCI.

The counterfactual abstracts from quantity responses in moving to the optimal plan. This implies that for households that realize an increase in the per-call price on the optimal plan, we underestimate the true extent of savings. For households with a decrease in the per-call price, however, the effect on savings is unclear: they save on preexisting usage, but also expand their usage in total in response to the lower price.

AT\&T and MCI engage in additional "off-plan" promotional activities to induce households to choose their service. Under the majority of such promotions, qualifying households receive a discount applied to their bill for a certain number of billing periods. Based on a comparison of data on AT\&T's and MCI's off-plan promotions during the sample period to the households' bills, none of the subscribers in the sample receives such bill credits. To the extent that households benefit from less common off-plan promotions, any consumer welfare gains we find represent a lower bound.

Heterogeneity in cost savings and possible explanations. The average household savings on AT\&T and MCI mask significant heterogeneity across households. Out of 592 AT\&T households in our sample, 331 households (56\%) save money by choosing AT\&T. Monthly savings for these households amount to $\$ 5.39$ on average and $\$ 4.44$ at the median. The vast majority is on one of AT\&T's flat-rate plans $(61.8 \%$ on local flat-rate service and $30.7 \%$ on bundled local and regional service), including 86 households in New York City where Verizon does not offer flat-rate service. The remainder of AT\&T subscribers incurs a higher bill, paying on average $\$ 4.24$ or $22 \%$ more than their expected payment to Verizon. Of these households, $81.2 \%$ also subscribe to AT\&T's local flat-rate plan, but only $3.8 \%$ use AT\&T's bundled local and regional plan.

Out of the $218 \mathrm{MCI}$ households, $63.8 \%$ save money by choosing MCI, with average monthly savings of $\$ 3.24$ and median savings of $\$ 2.25$. The remaining MCI households incur on average additional charges of $\$ 4.59$ or $19 \%$ of the price they would pay on Verizon. The propensity to incur such additional charges differs by plan type. Only $29 \%$ of households on a metered plan and $34 \%$ of households on a hybrid plan overpay by choosing MCI compared to $54 \%$ of households on flat-rate service.

We also compare bill amounts of households that use Verizon for local service to the expected bill they would incur on AT\&T or MCI. Verizon's service is on average $\$ 1.68$ or $3.8 \%$ cheaper than equivalent charges for the household's realized usage on the least costly, contemporaneous 
plan offered by one of the entrants. We again find significant heterogeneity in savings across households with $40 \%$ of households losing $\$ 3.85$, on average, by not leaving Verizon.

There are a number of reasons why a household may choose a particular carrier even though it is not the cheapest provider. Inertia or high deliberation costs of evaluating the prices of various calling plans could lead consumers to keep a more expensive plan. Because all subscribers start out as Verizon consumers, inertia would lead to such instances being more frequent among households that remain with Verizon even after the introduction of the entrants' services.

A second explanation lies in demand uncertainty. Because the household commits to a provider and a plan before making calls, the household's choice may be optimal based on expected usage, but unpredictable demand for calls causes the chosen plan to not be the least expensive ex post. Miravete (2002a) studies the effect that uncertainty over usage has on plan choice. He finds that consumers make, on average, the correct plan choice conditional on their realized consumption, despite their uncertain usage. Consumers frequently switch calling plans, with the goal of minimizing cost of service in response to small differences in cost. ${ }^{5}$ Although demand uncertainty represents a rational explanation for the choice of a more expensive plan, DellaVigna and Malmendier (2006) suggest that consumers systematically over- or underpredict usage and that firms adjust their pricing strategies to lock these consumers into suboptimal plans.

A last explanation is quality differentiation by firms, whereby any overpayment represents the consumer's willingness to pay for higher quality of service or firm reputation. Because the entrants lease Verizon's infrastructure for call and add-on feature provision, the quality of call provision is similar across firms and regulated by the NYPSC to prevent service deterioration. ${ }^{6}$ Firms differentiate their services through differences in customer service quality and in the variety of calling plans offered. In addition, consumers may have perceptions of the carriers' quality based on prior experience with the entrants' long-distance services.

We provide several forms of evidence of the drivers of household carrier choices to inform our econometric model in Section 5. We begin with simple tabulations of the frequencies and magnitudes of household overpayments, relative to the cheapest option available during the household's billing period. Table 4 summarizes the overpayments normalized by the cost of the least expensive option, distinguishing between households that could realize savings by switching carriers and those that could do so by simply switching to a different plan offered by the same provider. To assess the latter, we evaluate whether households on metered service would pay less on the provider's flat-rate plan, if available, given their monthly usage.

The share of households with potential savings from adjusting their provider choice, approximately $40 \%$ across providers, far exceeds the share of households that could save from switching among the chosen provider's plans, with t-statistics for tests of differences in mean frequencies of 5.85 for AT\&T, 4.66 for MCI, and 19.35 for Verizon households. The magnitudes of the potential savings, however, are similar. The fact that a household's choice of calling plan among its carrier's offerings is frequently correct, relative to its choice of carrier, suggests that demand uncertainty or consumer irrationality are not very significant in biasing the choice of plan. Corroborating evidence that demand uncertainty is relatively unimportant is the number of households choosing a more expensive flat-rate plan. Of AT\&T households with potential cost savings, $87 \%$ choose AT\&T's flat-rate plan despite the availability of Verizon's lower-priced flat-rate service, while among the corresponding group of MCI households, $20 \%$ choose flat-rate service in areas where Verizon offers a lower-cost flat-rate option. Further, we interpret this as evidence that perceived differences in provider quality influence the household's provider choice. This is particularly true for households that choose flat-rate service, which eliminates

${ }^{5}$ His findings contradict Hobson and Spady (1988) and Kling and Van der Ploeg (1990), who document a consumer bias toward choosing a flat-rate option that does not minimize their bill, but this evidence comes from data collected shortly after the introduction of optional local metered service and may represent a transitory effect.

${ }^{6}$ There is little evidence of competition through innovation in or variety of add-on features. During the time period of our sample, Verizon does not introduce significant new add-on features, nor do we observe differences in the variety of add-on feature bundles offered across providers. 
TABLE 4 Overpayments Made by Households

\begin{tabular}{|c|c|c|c|c|c|c|}
\hline Category & $\begin{array}{l}\text { Switching } \\
\text { to AT\& } T^{\text {a }}\end{array}$ & $\begin{array}{l}\text { Switching } \\
\text { to } \mathrm{MCI}^{\mathrm{a}}\end{array}$ & $\begin{array}{c}\text { Not Switching } \\
\text { to AT\&T } \\
\text { or } \mathrm{MCI}^{\mathrm{b}}\end{array}$ & $\begin{array}{l}\text { Within } \\
\text { AT\&T }^{\mathrm{c}}\end{array}$ & $\begin{array}{l}\text { Within } \\
\text { Verizon }^{\mathrm{d}}\end{array}$ & $\begin{array}{l}\text { Within } \\
\mathrm{MCI}^{\mathrm{e}}\end{array}$ \\
\hline $\begin{array}{l}\text { Frequency } \\
\quad \text { (Standard Deviation) }\end{array}$ & $\begin{array}{c}0.44 \\
(0.50)\end{array}$ & $\begin{array}{c}0.36 \\
(0.48)\end{array}$ & $\begin{array}{c}0.40 \\
(0.49)\end{array}$ & $\begin{array}{c}0.12 \\
(0.33)\end{array}$ & $\begin{array}{c}0.17 \\
(0.37)\end{array}$ & $\begin{array}{r}0.10 \\
(0.30)\end{array}$ \\
\hline Mean & -0.22 & -0.19 & -0.14 & -0.38 & -0.23 & -0.32 \\
\hline Standard Deviation & 0.44 & 0.19 & 0.11 & 0.30 & 0.16 & 0.23 \\
\hline Median & -0.14 & -0.10 & -0.12 & -0.47 & -0.22 & -0.40 \\
\hline Minimum & -6.36 & -0.90 & -0.71 & -0.78 & -0.71 & -0.49 \\
\hline Maximum & -0.00 & -0.01 & -0.00 & -0.01 & -0.00 & -0.06 \\
\hline$N$ & 592 & 218 & 3981 & 42 & 1750 & 32 \\
\hline
\end{tabular}

${ }^{\mathrm{a}}$ As fraction of predicted total Verizon charges.

${ }^{\mathrm{b}}$ As fraction of predicted charges on optimal AT\&T or MCI plan.

${ }^{\mathrm{c}}$ As fraction of predicted charges on optimal AT\&T flat-rate plan.

${ }^{\mathrm{d}}$ As fraction of predicted charges on optimal Verizon flat-rate plan.

${ }^{\mathrm{e}}$ As fraction of predicted charges on optimal MCI flat-rate plan.

any effect of unexpected demand fluctuations on price paid. Table 4 also provides evidence that consumer inertia in decision making does not play a major role. Households that choose AT\&T, for example, are more likely to overpay for their service than Verizon households, even though their choice indicates a willingness to search for a new provider and less inertia than the Verizon households.

We now investigate characteristics of households that do not choose the least-expensive provider in a probit model. In addition to demographic characteristics, we control for prior experience that the household has with AT\&T or MCI by including indicator variables for whether the household uses AT\&T or MCI for its long-distance service. ${ }^{7}$ Table 5 displays the results of this probit model, allowing the coefficients to differ across chosen carrier.

There are few characteristics that predict the household's likelihood not to choose the leastexpensive carrier. Households that moved in the last year are statistically and economically less likely to overpay for local service, possibly contradicting the finding above that inertia is not significant in driving household biases. Diverging results emerge for most other demographic characteristics. Whereas Verizon's minority households are statistically more likely to overpay as a result of their carrier choice, their AT\&T counterparts are statistically less likely to do so. Similarly, larger households, possibly experiencing larger demand fluctuations, are more likely to choose MCI erroneously, while the opposite holds for Verizon. Overall, the variances explained by the probit models are very low, with likelihood ratio indices of 0.09 for AT\&T households, 0.19 for MCI households, and 0.13 for Verizon households, ${ }^{8}$ providing little evidence of suboptimal choice behavior by certain demographic groups or successful targeting by the providers of consumers based on observable characteristics.

The probit regressions also control for seasonality that induces demand variation over months. If the seasonal controls explained a large share of the variance, it would be an indication that households choose calling plans based on expected usage over the course of the year as opposed to adjusting their plan choice in response to seasonal variation in usage (as we assume in our model in Section 5). The monthly dummies only account for an increase in the likelihood ratio index from 0.06 to 0.09 for AT\&T customers, from 0.13 to 0.19 for MCI customers, and

\footnotetext{
${ }^{7}$ We thus assume that households made their long-distance provider choice of AT\&T or MCI prior to choosing the carriers as their local service providers.

${ }^{8}$ We use McFadden's (1974) likelihood ratio index, defined as $L R I=1-\frac{\ln \left[L_{1}\right]}{\ln \left[L_{0}\right]}$, where $L_{0}$ is the log-likelihood computed with only a constant term and $L_{1}$ is the log-likelihood of the full model.
} 
TABLE 5 Probit Estimates of Mistaken Provider Choice

\begin{tabular}{|c|c|c|c|c|c|c|}
\hline \multirow[b]{3}{*}{ Variable } & \multicolumn{6}{|c|}{ Mistaken Provider Choice Y/N } \\
\hline & \multicolumn{2}{|c|}{ AT\&T Customers } & \multicolumn{2}{|c|}{ MCI Customers } & \multicolumn{2}{|c|}{ Verizon Customers } \\
\hline & $\begin{array}{c}\text { Coefficient } \\
\text { (Standard Error) }\end{array}$ & $\begin{array}{l}\text { Marginal } \\
\text { Effect }^{\mathrm{a}}\end{array}$ & $\begin{array}{c}\text { Coefficient } \\
\text { (Standard Error) }\end{array}$ & $\begin{array}{l}\text { Marginal } \\
\text { Effect }^{\mathrm{a}}\end{array}$ & $\begin{array}{c}\text { Coefficient } \\
\text { (Standard Error) }\end{array}$ & $\begin{array}{c}\text { Marginal } \\
\text { Effect }^{\mathrm{a}}\end{array}$ \\
\hline INTERNET & $\begin{array}{c}0.1003 \\
(0.1236)\end{array}$ & 0.0394 & $\begin{array}{c}0.2480 \\
(0.2406)\end{array}$ & 0.0891 & $\begin{array}{l}0.1124^{* *} \\
(0.0513)\end{array}$ & 0.0428 \\
\hline CELLULAR & $\begin{array}{c}-0.0712 \\
(0.1218)\end{array}$ & -0.0279 & $\begin{array}{r}-0.0263 \\
(0.2203)\end{array}$ & -0.0094 & $\begin{array}{l}0.1406^{* * *} \\
(0.0510)\end{array}$ & 0.0536 \\
\hline HHSIZE & $\begin{array}{r}-0.0282 \\
(0.0530)\end{array}$ & -0.0111 & $\begin{array}{l}0.3212^{* * *} \\
(0.1009)\end{array}$ & 0.1153 & $\begin{array}{l}-0.1067^{* * *} \\
(0.0209)\end{array}$ & -0.0405 \\
\hline INCOME & $\begin{array}{r}-0.0290 \\
(0.0191)\end{array}$ & -0.0114 & $\begin{array}{c}-0.0395 \\
(0.0352)\end{array}$ & -0.0142 & $\begin{array}{l}0.0599^{* * *} \\
(0.0074)\end{array}$ & 0.0227 \\
\hline AGE (15-34) & $\begin{array}{l}-0.7495^{* * *} \\
(0.2321)\end{array}$ & -0.2601 & $\begin{array}{r}-0.1768 \\
(0.3606)\end{array}$ & -0.0614 & $\begin{array}{c}0.0519 \\
(0.0775)\end{array}$ & 0.0198 \\
\hline AGE (35-54) & $\begin{array}{c}-0.1252 \\
(0.1414)\end{array}$ & -0.0489 & $\begin{array}{c}0.1391 \\
(0.2241)\end{array}$ & 0.0504 & $\begin{array}{c}0.0618 \\
(0.0501)\end{array}$ & 0.0235 \\
\hline MOVED1Y & $\begin{array}{c}-0.8651^{* * *} \\
(0.3580)\end{array}$ & -0.2850 & $\begin{array}{l}-1.0462^{* * *} \\
(0.6943)\end{array}$ & -0.2636 & $\begin{array}{c}-0.2725^{* * *} \\
(0.1050)\end{array}$ & -0.0983 \\
\hline BLACK & $\begin{array}{c}-0.7006^{* * *} \\
(0.2176)\end{array}$ & -0.2460 & $\begin{array}{c}0.2341 \\
(0.3886)\end{array}$ & 0.0874 & $\begin{array}{l}0.8210^{* * * *} \\
(0.0949)\end{array}$ & 0.3183 \\
\hline HISPANIC & $\begin{array}{c}-0.6582^{* *} \\
(0.3449)\end{array}$ & -0.2303 & $\begin{array}{r}-0.4803 \\
(0.5697)\end{array}$ & -0.1525 & $\begin{array}{l}0.6743^{* * *} \\
(0.1021)\end{array}$ & 0.2639 \\
\hline RACEO & $\begin{array}{c}0.2013 \\
(0.3455)\end{array}$ & 0.0799 & $\begin{array}{c}0.4570 \\
(0.4692)\end{array}$ & 0.1743 & $\begin{array}{l}0.2190^{* *} \\
(0.1027)\end{array}$ & 0.0851 \\
\hline SAMLD & $\begin{array}{l}-0.6738^{* * *} \\
(0.2571)\end{array}$ & -0.2630 & $\begin{array}{l}1.2367^{* * *} \\
(0.4730)\end{array}$ & 0.3257 & & \\
\hline $\begin{array}{l}(1-\text { SAMLD }) \times \\
\text { SAMBILL }\end{array}$ & $\begin{array}{c}-0.4946 \\
(0.3426)\end{array}$ & -0.1805 & $\begin{array}{l}1.5151^{* * *} \\
(0.6197)\end{array}$ & 0.5409 & $\begin{array}{r}-0.0470 \\
(0.0597)\end{array}$ & -0.0178 \\
\hline$N$ & 592 & & 218 & & 3981 & \\
\hline $\begin{array}{l}\text { Log-likelihood } \\
p \text {-value }\end{array}$ & $\begin{array}{r}-367.7 \\
0.0000\end{array}$ & & $\begin{array}{r}-116.3 \\
0.0006\end{array}$ & & $\begin{array}{r}-2320.9 \\
0.0000\end{array}$ & \\
\hline $\begin{array}{l}\text { Likelihood } \\
\text { Ratio index }\end{array}$ & 0.0947 & & 0.1854 & & 0.1325 & \\
\hline
\end{tabular}

A household is classified as having made a mistaken provider choice if it subscribes to a provider whose pricing plans are not the least expensive for the household's ex post usage. Monthly dummies and a dummy for September and October 2001 are included in the estimation. Dummy variables are included to control for missing data for the MOVED1Y, SAMLD, and SAMBILL variables.

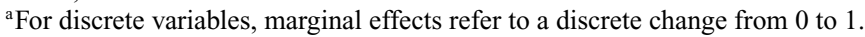

* Significant at the $10 \%$ level.

** Significant at the $5 \%$ level.

${ }^{* * *}$ Significant at the $1 \%$ level.

from 0.11 to 0.13 for Verizon customers. It appears that anticipated seasonal demand fluctuation is, therefore, not very important in driving provider choices.

To test for the importance of consumer learning, in an alternative unreported model we include time since the entrants' inception of service and time since a price change, both measured in days, as explanatory variables. The results indicate that for every 100 days since AT\&T's entry, a household's likelihood of erroneously choosing AT\&T decreases by 2.0 percentage points, providing statistically significant evidence of some extent of household learning. The overall explanatory power of the model does not improve significantly, however, resulting in a likelihood ratio index of 0.11 . For MCI, in contrast, the probability of mistakes in the provider choice increases by 3.8 percentage points for every 100 days since MCI's entry. Across providers, thus, we do not find consistent, practical significance of learning.

As a last piece of descriptive evidence of determinants of carrier choice, we estimate a multinomial logit model of provider choice, using Verizon as the base category. The results are 
TABLE 6 Multinomial Estimates of Switching to Entrants

\begin{tabular}{|c|c|c|c|c|}
\hline \multirow[b]{2}{*}{ Variable } & \multicolumn{2}{|c|}{ Choice $=$ AT\&T } & \multicolumn{2}{|c|}{ Choice $=$ MCI } \\
\hline & $\begin{array}{c}\text { Coefficient } \\
\text { (Standard Error) }\end{array}$ & $\begin{array}{l}\text { Marginal } \\
\text { Effect }^{\mathrm{a}}\end{array}$ & $\begin{array}{c}\text { Coefficient } \\
\text { (Standard Error) }\end{array}$ & $\begin{array}{l}\text { Marginal } \\
\text { Effect }^{\mathrm{a}}\end{array}$ \\
\hline INTERNET & $\begin{array}{c}-0.0752 \\
(0.1340)\end{array}$ & -0.0054 & $\begin{array}{l}-0.3828 \\
(0.2337)\end{array}$ & -0.0061 \\
\hline CELLULAR & $\begin{array}{c}0.0939 \\
(0.1282)\end{array}$ & 0.0075 & $\begin{array}{r}-0.0094 \\
(0.2175)\end{array}$ & -0.0003 \\
\hline NYCITY & $\begin{array}{l}-0.7183^{* *} \\
(0.2958)\end{array}$ & -0.0488 & $\begin{array}{r}-0.0546 \\
(0.4627)\end{array}$ & 0.0000 \\
\hline HHSIZE & $\begin{array}{l}0.2563^{* * *} \\
(0.0611)\end{array}$ & 0.0200 & $\begin{array}{r}0.1834^{*} \\
(0.1064)\end{array}$ & 0.0027 \\
\hline $\begin{array}{l}\text { NYCITY } \times \\
\text { HHSIZE }\end{array}$ & $\begin{array}{c}0.0399 \\
(0.1188)\end{array}$ & 0.0034 & $\begin{array}{r}-0.1694 \\
(0.2163)\end{array}$ & -0.0029 \\
\hline INCOME & $\begin{array}{c}-0.0972^{* * *} \\
(0.0205)\end{array}$ & -0.0076 & $\begin{array}{r}-0.0570^{*} \\
(0.0339)\end{array}$ & -0.0008 \\
\hline AGE (15-34) & $\begin{array}{c}0.1934 \\
(0.2248)\end{array}$ & 0.0157 & $\begin{array}{c}0.3036 \\
(0.3400)\end{array}$ & 0.0053 \\
\hline AGE (35-54) & $\begin{array}{c}0.0039 \\
(0.1356)\end{array}$ & 0.0004 & $\begin{array}{r}-0.0897 \\
(0.2219)\end{array}$ & -0.0015 \\
\hline MOVED1Y & $\begin{array}{c}0.1122 \\
(0.3156)\end{array}$ & 0.0094 & $\begin{array}{r}-0.0969 \\
(0.5539)\end{array}$ & -0.0017 \\
\hline BLACK & $\begin{array}{l}0.5090^{* *} \\
(0.2274)\end{array}$ & 0.0483 & $\begin{array}{r}-0.0982 \\
(0.3970)\end{array}$ & -0.0024 \\
\hline HISPANIC & $\begin{array}{c}-0.6294^{* *} \\
(0.2923)\end{array}$ & -0.0393 & $\begin{array}{l}-0.4645 \\
(0.5081)\end{array}$ & -0.0058 \\
\hline RACEO & $\begin{array}{c}-0.3597 \\
(0.3304)\end{array}$ & -0.0271 & $\begin{array}{l}1.1756^{* * *} \\
(0.4436)\end{array}$ & 0.0348 \\
\hline ATTLD & $\begin{array}{l}3.0470^{* * *} \\
(0.1507)\end{array}$ & 0.3526 & $\begin{array}{l}-0.3956 \\
(0.4333)\end{array}$ & -0.0118 \\
\hline MCILD & $\begin{array}{c}0.0596 \\
(0.4139)\end{array}$ & -0.0341 & $\begin{array}{l}4.3002^{* * *} \\
(0.2469)\end{array}$ & 0.4224 \\
\hline $\begin{array}{l}(1-\text { SAMLD }) \times \\
\text { SAMBILL }\end{array}$ & $\begin{array}{c}-1.3762^{* * *} \\
(0.2148)\end{array}$ & -0.0742 & $\begin{array}{c}-1.7875^{* * *} \\
(0.3528)\end{array}$ & -0.0173 \\
\hline$N$ & & 3164 & & \\
\hline Log-likelihood & & -1350.35 & & \\
\hline$p$-value & & 0.0000 & & \\
\hline Likelihood ratio index & & 0.4055 & & \\
\hline
\end{tabular}

The analysis is based on those households that live in an area where all three carriers offered service at the time of the household's bill. Monthly dummies and a dummy for September and October 2001 are included in the estimation. Dummy variables are included to control for missing data for the MOVED1Y, SAMLD, and SAMBILL variables.

${ }^{a}$ For discrete variables, marginal effects refer to a discrete change from 0 to 1 .

* Significant at the $10 \%$ level.

** Significant at the $5 \%$ level.

*** Significant at the $1 \%$ level.

in Table 6. Relative to the low predictive power of the probit models, household characteristics explain a significant fraction of the variance in choice behavior, with a likelihood ratio index of 0.41 . Several characteristics, such as income, household size, and race, are statistically but not practically significant in explaining a household's decision to choose an entrant. Most significant, both statistically and economically, is whether the household has prior experience with the provider through a subscription to its long-distance service and whether the household receives a common bill for its local and long-distance service but uses two different providers. Households with AT\&T as their long-distance provider are 35.3 percentage points more likely to choose AT\&T as their local provider, whereas the equivalent figure is 42.2 percentage points for MCI. The results are consistent with a number of interpretations including the entrants marketing their local service more aggressively to preexisting long-distance customers, consumer benefits from receiving a 
single bill, and perceived quality differences that induce household sorting into providers. The last possibility suggests possible strategic benefits from bundling the two services. Households that receive a single bill but utilize different service providers are less likely to switch to an entrant, reflecting the fact that they incur charges from the entrants for this convenience while Verizon, due to regulation, offers this service at no additional charge.

Taken all together, these results are consistent with households that already use one of the entrants as their long-distance provider attributing a higher perceived quality to that firm than other households. Because the evidence points toward differences in firm quality as contributing to suboptimal provider choices across households, we allow for firm differentiation effects in our econometric model. We ignore inertia and demand uncertainty as being of second-order importance only.

\section{Demand model}

- In estimating local telecommunications demand, the literature accommodates the presence of nonlinear tariffs in several ways. Train, McFadden, and Ben-Akiva (1987) employ a nested logit structure to estimate demand for local phone service in which each nest is a combination of a plan and a portfolio of calls (number and distance). The immense number of possible portfolios limits the applicability of the technique. Miravete (2002b) instead infers the distribution of consumers' utility for local phone calls by incorporating the time lag between the initial plan choice and the subsequent usage decision. He identifies differences in the distribution of consumer types before and after a change in plan offerings and analyzes the extent of usage-based discrimination by the local phone company.

A second strand of the literature models local telecommunications demand as a mixed discrete/continuous model, building upon earlier empirical work by Dubin and McFadden (1984), Dubin (1985), Chiang (1991), and Chiang and Lee (1992). One example is the study of local phone service penetration by Hausman, Tardiff, and Belinfante (1993). Due to lack of usage data, they estimate only the discrete portion of the model, but incorporate in it the usage choice consistent with utility maximization. Narayanan, Chintagunta, and Miravete (2007) use a model similar to ours to study the extent of consumer learning about usage after a new plan introduction. In contrast to their setting, the types of available calling plans remain virtually unchanged both prior to and during our sample period and any consumer learning is therefore likely to have occurred already. Instead, we focus on the effect of competition on consumers' plan and usage choices and on modelling bundling of local and regional calling as potential sources of welfare gains for consumers.

Household choice problem. In this section, we derive the optimal calling plan and consumption choices for local, $L$, and regional, $R$, service. We consider households indexed by $i=1,2, \ldots, I_{m}$ in $m=1,2, \ldots, M$ markets. The households choose a plan from the set of available plans, indexed by $j=1,2, \ldots, J_{m}$, offered by firms $f=1,2, \ldots, F_{m}$, and the quantity of local calls $q_{i j}^{L}$ and regional calls $q_{i j}^{R}$ they consume on the plan. To consume on plan $j$, consumers must pay a fixed fee, $P_{j m}$, a per-call local price of $p_{j m}^{L}$, and a per-call regional price of $p_{j m}^{R}$. Consumers spend the remainder of their income on an outside good $q^{O}$. Because approximately $95 \%$ of New York households subscribe to landline telephone service and less than $3 \%$ of cellular subscribers had fully displaced their landline by March 2002, we do not incorporate the outside option of not subscribing to telephone service. Lack of data on cellular usage beyond ownership also forces us to abstract from possible substitution between cellular and landline usage.

Households have a choice of up to three types of plans per carrier: metered, flat-rate, and hybrid. On a metered plan, households pay $p_{j m}>0$ per call regardless of total usage and pay a fixed fee of $P_{j m} \geq 0$. On a flat-rate plan, consumers pay nothing for usage $\left(p_{j m}=0\right)$ but incur a fixed fee of $P_{j m}>0$. On hybrid plans, households pay a fixed fee $P_{j m}>0$ and pay nothing $\left(p_{j m}=\right.$ 0 ) for usage below a threshold $\tilde{q}_{j m}$ but pay $\tilde{p}_{j m}>0$ for usage above $\tilde{q}_{j m}$. Due to the fixed fee and 
the bundling of local and regional services, it is optimal for the household to consume on a single plan $j$. We assume that household $i$ chooses that plan $j$ that maximizes its utility

$$
\begin{aligned}
u\left(q_{i j}^{L}, q_{i}^{O}, q_{i j}^{R}\right)= & q_{i}^{O}+\frac{1}{b^{L}}\left(a_{i}^{L} q_{i j}^{L}-\frac{\left(q_{i j}^{L}\right)^{2}}{2}\right)+\frac{1}{b^{R}}\left(a_{i}^{R} q_{i j}^{R}-\frac{\left(q_{i j}^{R}\right)^{2}}{2}\right) \\
& -\frac{\left(a_{i}^{L}\right)^{2}}{2 b^{L}}-\frac{\left(a_{i}^{R}\right)^{2}}{2 b^{R}}+\zeta_{i f}+\epsilon_{i j} \\
& a_{i}^{L}, a_{i}^{R}, b_{i}^{L}, b_{i}^{R}>0 ; q_{i j}^{L} \leq a_{i}^{L}, q_{i j}^{R} \leq a_{i}^{R},
\end{aligned}
$$

subject to the budget constraint

$$
y_{i} \geq q_{i}^{O}+P_{j m}+p_{j m}^{R} q_{i j}^{R}+p_{j m}^{L} q_{i j}^{L}\left(1-I_{j m}^{H}\right)+\tilde{p}_{j m}^{L} \max \left(q_{i j}^{L}-\tilde{q}_{j m}^{L}, 0\right) I_{j m}^{H} .
$$

In equation (1), the first term represents the utility obtained from the outside good whose price we normalize to one. The second and third components measure the utility obtained from local and regional usage, respectively, as a function of the demand parameters $a_{i}^{T}$ and $b_{i}^{T}, T=\{L, R\}$. $\zeta_{\text {if }}$ is household $i$ 's perceived quality of firm $f$ and $\epsilon_{i}$ is a $J \times 1$ vector of unobservable plan preferences, which we assume to be distributed according to a type-1 extreme-value distribution. The budget constraint incorporates the within-plan nonlinear pricing of hybrid plans $\left(I_{j m}^{H}=1\right)$ via the call allowance, $\tilde{q}_{j m}^{L}$. Conditional on the choice of plan $j$, the demand for usage of type $T$ equals

$$
q_{i j}^{T}\left(p_{j m}^{T}\right)= \begin{cases}a_{i}^{T}-b^{T} p_{j m}^{T} & \text { if } p_{j m}^{T}<\frac{a_{i}^{T}}{b^{T}} \\ 0 & \text { otherwise }\end{cases}
$$

If a household chooses a flat-rate plan or a hybrid plan where it remains within the call allowance, the demand function simplifies to

$$
q_{i j}^{T}\left(p_{j m}^{T}=0\right)=a_{i}^{T} .
$$

We set the household's local usage on hybrid plans equal to the allowance $\tilde{q}_{j m}^{L}$ if the household's optimal quantity based on equation (3) at $\tilde{p}_{j m}^{L}$ falls short of the allowance, but the optimal quantity based on a zero per-call price (equation (4)) exceeds the allowance.

Substituting these conditional demand functions into the household's utility function yields a set of conditional indirect utility functions that vary with the household's choice of plan and usage patterns. For a household with positive usage of local and regional service, the conditional indirect utility function is given by

$$
\begin{aligned}
& v_{i j}\left(P_{j m}, p_{j m}^{L}, \tilde{p}_{j m}^{L}, \tilde{q}_{j m}^{L}, p_{j m}^{R}, y_{i}\right) \\
& =\left\{\begin{aligned}
y_{i}-P_{j m}-\left(a_{i}^{R}-\frac{1}{2} b^{R} p_{j m}^{R}\right) p_{j m}^{R}-\left(a_{i}^{L}-\frac{1}{2} b^{L} p_{j m}^{L}\right) p_{j m}^{L}+\zeta_{i f}+\epsilon_{i j} \\
\text { if } \tilde{q}_{j m}=0 \text { or } a_{i}^{L}-b^{L} \tilde{p}_{j m}^{L} \leq \tilde{q}_{j m} \\
y_{i}-P_{j m}-\left(a_{i}^{R}-\frac{1}{2} b^{R} p_{j m}^{R}\right) p_{j m}^{R}-\left(a_{i}^{L}-\frac{1}{2} b^{L} \tilde{p}_{j m}^{L}-\tilde{q}_{j m}\right) \tilde{p}_{j m}^{L}+\zeta_{i f}+\epsilon_{i j} \\
\text { if } 0<\tilde{q}_{j m}<a_{i}^{L}-b^{L} \tilde{p}_{j m}^{L} .
\end{aligned}\right.
\end{aligned}
$$

The top line displays the indirect utility if the household chooses a flat-rate or metered plan or a hybrid plan but consumes less than the allowance. The bottom line applies to households on hybrid plans that consume in excess of the allowance. Corner solutions arise in the data for regional calls. As shown in Table 2, 65.5\% of households make no regional calls, whereas 
all households have some local usage. With zero regional calls, the indirect utility function equals

$$
v_{i j}\left(P_{j m}, p_{j m}^{L}, \tilde{p}_{j m}^{L}, \tilde{q}_{j m}^{L}, p_{j m}^{R}, y_{i}\right)=\left\{\begin{array}{c}
y_{i}-P_{j m}-\left(a_{i}^{L}-\frac{1}{2} b^{L} p_{j m}^{L}\right) p_{j m}^{L}+\zeta_{i f}+\epsilon_{i j} \\
\text { if } \tilde{q}_{j m}=0 \text { or } a_{i}^{L}-b^{L} \tilde{p}_{j m}^{L} \leq \tilde{q}_{j m} \\
y_{i}-P_{j m}-\left(a_{i}^{L}-\frac{1}{2} b^{L} \tilde{p}_{j m}^{L}-\tilde{q}_{j m}\right) \tilde{p}_{j m}^{L}+\zeta_{i f}+\epsilon_{i j} \\
\text { if } 0<\tilde{q}_{j m}<a_{i}^{L}-b^{L} \tilde{p}_{j m}^{L} .
\end{array}\right.
$$

We allow the demand intercepts, $a^{T}$, to vary as a function of the household's observable and unobservable characteristics. For the demand functions to be well defined, we restrict $a_{i}^{T}$ to be positive by specifying it as an exponential function of the household's characteristics

$$
\ln \left(a_{i}^{T}\right)=\alpha^{T}+\alpha_{D}^{T} D_{i}+v_{i}^{T},
$$

where $\alpha^{T}$ and $\alpha_{D}^{T}$ are parameters and $D_{i}$ is a column-vector of characteristics for household $i$. We assume that household $i$ 's demand intercept contains an unobservable household taste for local or regional usage, $v_{i}^{T}$. The vector $v_{i}$ captures unobserved household characteristics that affect demand for local and regional calls, such as the size of the household's network of contacts in the area. We assume that the unobserved characteristics $v_{i}=\left[v_{i}^{L}, v_{i}^{R}\right]^{\prime}$ are identically distributed according to a bivariate normal distribution with mean zero and variance-covariance matrix

$$
\Sigma_{v}=\left[\begin{array}{cc}
\sigma_{L}^{2} & \rho \sigma_{L} \sigma_{R} \\
\rho \sigma_{L} \sigma_{R} & \sigma_{R}^{2}
\end{array}\right] .
$$

Equation (7) implies that the demand error, $v_{i}^{T}$, equals

$$
\begin{aligned}
v_{i}^{T} & =\ln \left(a_{i}^{T}\right)-\alpha^{T}-\alpha_{D}^{T} D_{i} \\
& =\ln \left(q_{i j}^{T}+b^{T} p_{j m}\right)-\alpha^{T}-\alpha_{D}^{T} D_{i} .
\end{aligned}
$$

Last, we decompose household $i$ 's perceived quality of firm $f$ into observable firm characteristics and an unobservable firm-level characteristic by parameterizing $\zeta_{\text {if }}$ as

$$
\zeta_{i f}=\lambda_{f}^{\prime} Z_{i}+\xi_{f m},
$$

with $\lambda_{f}$ denoting a $z \times 1$ vector of parameters. Demographic shifters, $Z_{i}$, control for differences in horizontal preferences for a provider among households, for example based on the household's experience with the provider for a different type of service. $\xi_{f m}$ represents an unobserved contribution to firm quality, such as the quality of the provider's customer service. This characteristic varies at the level of the firm/market, but not at the level of the plan. It is the same for all households in the market, representing a vertical attribute of the provider.

The unobservable components in $a_{i}^{T}$ affect the quantity consumed, but the discrete choice only indirectly through the quantity choice. They vary by household, but not by plan, through $v_{i}^{T}$. The unobservable components $\xi_{f m}$ and $\epsilon_{i j}$, on the other hand, affect only the discrete choice and not the quantity choice.

Similar to the discrete choice demand literature (Berry, 1994; Berry, Levinsohn, and Pakes, 1995, 2004; Goolsbee and Petrin, 2004; Nevo, 2001), the firm-level unobservable, $\xi_{f m}$, captures unobserved quality differences between firms within a market. The descriptive results presented above suggest that unobserved provider characteristics are important in driving household provider choices, which the prices charged by each provider might reflect. We model the unobservable as varying at the level of the firm only, instead of the level of the product, because calling plans are nonlinear pricing schemes that give the customer access to the same customer and billing services 
and quality of calls. This allows us to control for price endogeneity by including provider/market fixed effects in the household's indirect utility function. ${ }^{9}$

Because add-on features represent a significant portion of savings from price effects, it is important that we accommodate them in the econometric model. There are too many possible combinations of add-on features offered to estimate their choice by households explicitly. Instead, we assume that each household consumes an identical bundle of add-on features regardless of which carrier or plan it chooses. We adjust its budget constraint by the price for that bundle.

Our modelling framework corresponds to that in Hanemann (1984) for the case of mutual exclusivity whereby each consumer chooses to consume a continuous quantity from a single provider. Our work thus complements a number of recent papers that consider scenarios in which households choose an optimal number of discrete products (Chan, 2006; Dubé, 2004; Hendel, 1999) or multiple discrete products (Kim, Allenby, and Rossi, 2002). Whereas the quadratic utility function and the demand system imply a simple linear relationship between price and usage regardless of the price level, the utility function easily accommodates the following main features of the institutional setting. First, the specification allows for bundling of local and regional usage, but the consumption of one type of call does not affect the marginal utility obtained from the other. This ensures that the demands for local and regional calls are independent of each other. Second, marginal utility of calls declines with usage. This allows for satiation of demand on flat-rate plans with a zero marginal price because, at some point, the household spends so much time on the phone that it crowds out time spent on outside activities. Third, the utility function allows for the possibility of zero consumption (a corner solution) for both services.

Estimation procedure. The predictions from the model consist of an optimal plan choice and a corresponding usage choice for both local and regional service, as a function of the household's observable and unobservable characteristics, the firm's observable and unobservable attributes, and the plan's unobservable attributes. We use maximum likelihood methods to estimate the model. The full likelihood is the product of the likelihoods for each household across all markets

$$
\mathcal{L}\left(\Theta \mid d, \hat{q}^{L}, \hat{q}^{R}, X\right)=\prod_{m=1}^{M} \prod_{i=1}^{I_{m}} l_{i m}\left(\Theta \mid d_{i m}, \hat{q}_{i j m}^{L}, \hat{q}_{i j m}^{R}, X_{i m}\right),
$$

where the model's parameters are collapsed into the vector $\Theta$ and $X$ contains the $I_{m} \times M$ vectors of household characteristics, $D$, the $J_{m} \times M$ vectors of the plans' pricing components, $P, p, \tilde{p}$, and $\tilde{q}$, and the $F_{m} \times I_{m} \times M$ vector of firm/household characteristics, $Z$. $d$ is the vector of the household's observed plan choices across plans in its market, and $\hat{q}^{L}$ and $\hat{q}^{R}$ denote its observed usage.

The log-likelihood function for the household is the log of the joint probability of the household's plan choice, $d_{i}$, and its quantity choices, $\hat{q}_{i j}^{L}$ and $\hat{q}_{i j}^{R}$. We assume independence between the choice and usage shocks. The choice shock takes the role of unobserved preferences for a specific plan due to, for example, exposure to plan-specific advertising. Correlation between the choice and usage shocks could arise if the provider ran user- and plan-specific advertising campaigns and decided to promote certain plans specifically to households with a particular usage profile. We do not believe such correlations to be very significant in our application. Therefore, the joint probability is the product of the probability that household $i$ chooses plan $j$ conditional on $\hat{q}_{i j}$ and the probability density of $\hat{q}_{i j}$. Household $i$ 's contribution to the log-likelihood equals

$$
\ln \left[l_{i}\left(\Theta \mid d_{i}, \hat{q}_{i j}^{L}, \hat{q}_{i j}^{R}, X_{i}\right)\right]=\sum_{j=1}^{J} I_{d_{i j}} \ln \left\{f\left(d_{i j} \mid \hat{q}_{i j}, X_{i} ; \Theta\right) g\left(\hat{q}_{i j} \mid X_{i} ; \Theta\right)\right\},
$$

\footnotetext{
${ }^{9}$ Price endogeneity is potentially not severe because NYPSC regulates the incumbents's and, to a lesser extent, entrants' prices. We abstract from any remaining unobservable quality differences across plans offered by the same provider.
} 
suppressing market subscripts for ease of readability. $I_{d_{i j}}$ is an indicator variable set to one if household $i$ chooses plan $j$ and zero otherwise. $f\left(d_{i j} \mid \hat{q}_{i j}, X_{i} ; \Theta\right)$ denotes the conditional likelihood of observing household $i$ choosing plan $j$, while $g\left(\hat{q}_{i j} \mid X_{i} ; \Theta\right)$ denotes the likelihood of observing the usage of $\hat{q}_{i j}$ for local and regional service. For households that consume zero regional calls, equation (9) implies a value for the regional unobservable, $\hat{v}_{i}^{R}$, that is, the cutoff value for $v$ where usage is zero.

For any candidate values of the vector of parameters, $\Theta$, the probability that household $i$ chooses plan $j$ equals the integral over the distribution function of the choice shock

$$
f\left(d_{i j} \mid \hat{q}_{i j}, X_{i} ; \Theta\right)=\int_{C_{i j}} d F\left(\epsilon_{i} \mid v_{i}\left(\hat{q}_{i j}\right)\right),
$$

denoting as $C_{i j}=\left\{\left(v_{i}, X_{i}, \epsilon_{i 1}, \ldots, \epsilon_{i J}\right) \mid v_{i j} \geq v_{i k}, \hat{q}_{i j} \in S_{i j k}\left(v_{i}, X_{i}, \epsilon_{i} ; \Theta\right) \quad \forall k \neq j\right\}$ the set of individual preferences that lead to choice $j . S_{i j k}$ is the set of feasible quantity choices for household $i$ that are consistent with the household choosing plan $j$ over plan $k$. Ensuring that the observed quantity choices for local and regional usage fall within the feasible set places restrictions on the usage shock $\left(v_{i}\right)$ and unobserved plan preferences $\left(\epsilon_{i}\right)$. Thus, we impose two conditions on the individual preferences that lead to the choice of plan $j$ by household $i$ : plan $j$ must maximize indirect utility and observed usage must be consistent with plan $j$ being optimal.

To derive the set $S_{i j k}$, we solve for quantity cutoffs for local and regional usage such that the conditional indirect utility on plan $j$ exceeds that on plan $k$. These cutoffs are a function of the realized usage unobservable for the other service (i.e., $v\left(\hat{q}_{i j}^{L}\right)$ for regional usage and $v\left(\hat{q}_{i j}^{R}\right)$ for local usage), the difference in the unobserved plan preferences for plans $j$ and $k,\left(\epsilon_{i j}-\epsilon_{i k}\right)$, the quality differences between the plans' providers, the prices of plans $j$ and $k$, and the parameters. Depending on the relative per-call prices of the two plans, the quantity cutoff provides a minimum or maximum bound on observed quantity such that the indirect utility on plan $j$ equals that on plan $k$.

Using the constraint that the observed local quantity is consistent with the chosen plan, we can solve for the feasible range of individual preferences, $\epsilon$, that entail household $i$ choosing plan $j$ over plan $k$ and consuming its observed local usage ${ }^{10}$

$$
\begin{aligned}
\epsilon_{i j}-\epsilon_{i k} \geq & \hat{q}_{i j}^{L}\left(p_{j}^{L}-p_{k}^{L}\right)+\left(P_{j}^{L}-P_{k}^{L}\right)-\Delta \zeta_{i}-\frac{b^{L}}{2}\left[\left(p_{j}^{L}\right)^{2}-\left(p_{k}^{L}\right)^{2}\right] \\
& -\frac{b^{R}}{2}\left[\left(p_{j}^{R}\right)^{2}-\left(p_{k}^{R}\right)^{2}\right]+\exp \left[\alpha^{R}+\alpha_{D}^{R} D_{i}+v\left(\hat{q}_{i j}^{R}\right)\right]\left(p_{j}^{R}-p_{k}^{R}\right) \\
& +b^{L} p_{j}^{L}\left(p_{j}^{L}-p_{k}^{L}\right) \equiv \bar{m}_{i j k}^{L}\left(v\left(\hat{q}_{i j}^{R}\right), X_{i} ; \Theta\right),
\end{aligned}
$$

where $\Delta \zeta_{i}$ denotes the quality difference between the providers of plan $j$ and plan $k$. The constraint on the observed regional usage leads to a corresponding expression $\bar{m}_{i j k}^{R}\left(v\left(\hat{q}_{i j}^{L}\right), X_{i} ; \Theta\right)$ that can be formed by swapping $L$ and $R$ in the above expression. Appendix A provides the detailed derivation of equation (14). Because the constraint on $\epsilon_{i}$ must be met for both local and regional calls, $\epsilon_{i j}-\epsilon_{i k} \geq \max \left(\bar{m}_{i j k}^{L}, \bar{m}_{i j k}^{R}\right)$.

The regions of $\epsilon_{i}$ defined by equation (14) and the analogous expression for regional calls across all $k \neq j$ define $C_{i j}$. The fact that the unobserved plan preferences are distributed type- 1 extreme value implies that the difference between any two $\epsilon_{j}$ and $\epsilon_{k}$ follows a truncated logistic distribution with a truncation point of $\max \left(\bar{m}_{i j k}^{L}, \bar{m}_{i j k}^{R}\right)$. We apply a result from Maddala (1983) to derive an analytical expression for the integral in equation (13). Our assumption that $v_{i}$ and $\epsilon_{i}$ are independent simplifies this computation of choice probabilities greatly. The probability that household $i$ chooses plan $j$, conditional on the realization of the usage unobservable, is

$$
f\left(d_{i j} \mid \hat{q}_{i j}, X_{i} ; \Theta\right)=\frac{1}{\sum_{k=1}^{J} \exp \left[\max \left(\bar{m}_{i j k}^{L}\left(v\left(\hat{q}_{i j}^{R}\right), X_{i} ; \Theta\right), \bar{m}_{i j k}^{R}\left(v\left(\hat{q}_{i j}^{L}\right), X_{i} ; \Theta\right)\right)\right]} .
$$

\footnotetext{
${ }^{10}$ Equation (14) abstracts from hybrid plans. We discuss the equivalent expressions in Appendix A.
} 
We now derive the contribution to the likelihood of the households' usage decisions, $g\left(\hat{q}_{i j} \mid X_{i} ; \Theta\right)$, for the subset of households for whom we observe usage. In computing $g\left(\hat{q}_{i j} \mid X_{i} ; \Theta\right)$, we account for the fact that our data only provide truncated information on household usage. In particular, we do not observe the local usage of households that choose a flat-rate plan or a hybrid plan if their consumption remains within the plan's allowance. Under optimality, we can identify a quantity range into which the household's local usage has to fall for the chosen plan to maximize indirect utility. We then map the identified quantity ranges to corresponding ranges of the usage unobservable $v^{L}$ and compute the probability mass over the identified ranges for those plans for which we do not observe usage. We adjust the normal density of $v_{i}$ by this truncation mass in computing the likelihood $g\left(\hat{q}_{i j} \mid X_{i} ; \Theta\right)$.

To do this, we first determine the optimal plan over the entire support of $v^{L}$. We partition the $v^{L}$ support into $S$ segments such that plan $s$ is optimal over segment $s$ with end points $\bar{v}_{i}^{s}$ and $\bar{v}_{i}^{s+1}$, conditional on unobservable plan-specific preferences and the household's optimal regional usage on plan $s$. The number of segments does not necessarily equal the number of plans in the household's choice set, $J$, because some plans do not maximize utility for any $v_{i}^{L}$. We eliminate these dominated plans from the choice set. We next identify the plan that provides the highest indirect utility at $\bar{v}_{i}^{1}=-\infty$ and index this plan by $s=1$. We then compute the $v_{i}^{L}$ for which household $i$ is indifferent between plan $s$ and each of the plans remaining in the choice set. The upper cutoff to the range over which plan $s$ is optimal, $\bar{v}_{i}^{s+1}$, is the smallest of these indifference points. We similarly assign all remaining plans in the choice set to a segment of $v_{i}^{L}$.

We then compute the probability mass corresponding to those segments among $S$ for which our data do not contain usage observations. If plan $s$ is a flat-rate plan, we do not observe usage for any $v_{i}^{L}$ in segment $s$. If plan $s$ is a hybrid plan, we do not observe usage for the portion of segment $s$ that entails usage below the allowance. We denote by $U_{i}^{L}$ the probability of $v_{i}^{L}$ falling into any of the segments without usage data

$$
U_{i}^{L}=\int_{C_{i j}} \sum_{s \in S}\left(I_{s}^{F}+I_{s}^{H}\right)\left(\Phi\left(\frac{I_{s}^{F} \bar{v}_{i}^{s+1}+I_{s}^{H} \tilde{v}_{i}^{s+1}}{\sigma_{L}}\right)-\Phi\left(\frac{\bar{v}_{i}^{s}}{\sigma_{L}}\right)\right) d F\left(\epsilon_{i} \mid v_{i}\left(\hat{q}_{i j}\right)\right),
$$

where $I_{s}^{F}$ and $I_{s}^{H}$ are flat-rate and hybrid plan indicators. $\tilde{v}_{i}^{s+1}$ is the minimum of $\bar{v}_{i}^{s+1}$ and the $v_{i}^{L}$ value where usage equals $\tilde{q}_{s}$. Because the comparison of indirect utilities across plans depends on the differences in $\epsilon_{i}$, we integrate over the distribution of the unobservable plan preferences using simulation techniques to approximate $U_{i}^{L}$ numerically. Figure 3 illustrates the procedure for a household that chooses among a metered plan, a hybrid plan, and a flat-rate plan. Appendix B provides the detailed steps behind the estimation algorithm.

The contribution of the household's usage to the likelihood is

$$
g\left(\hat{q}_{i j} \mid X_{i} ; \Theta\right)=\left(\frac{1}{1-U_{i}^{L}}\right) \frac{\mathcal{J}_{i}}{(2 \pi)^{\frac{1}{2}}\left|\Sigma_{v}\right|^{\frac{1}{2}}} \exp \left\{\frac{-v_{i}\left(\hat{q}_{i j}\right)^{\prime} \Sigma_{v}^{-1} v_{i}\left(\hat{q}_{i j}\right)}{2}\right\}
$$

if $\hat{q}_{i j}^{R}>0$, and

$$
g\left(\hat{q}_{i j} \mid X_{i} ; \Theta\right)=\left(\frac{1}{1-U_{i}^{L}}\right)\left(1-\Phi\left(v_{i}^{R}\left(\hat{q}_{i j}^{R}=0\right)\right)\right) \frac{\mathcal{J}_{i}}{(2 \pi)^{\frac{1}{2}} \sigma_{L}} \exp \left\{\frac{-\left(v_{i}^{L}\left(\hat{q}_{i j}^{L}\right)\right)^{2}}{2 \sigma_{L}^{2}}\right\}
$$

if $\hat{q}_{i j}^{R}=0$. Here, $\Phi$ denotes the normal distribution function of $v^{R}$ conditional on $v^{L}$ and $\mathcal{J}_{i}$ is the Jacobian of the transformation from $v_{i}$ to $q_{i j}$.

When we do not observe the household's local usage, we compute the household's planchoice probability in equation (15) by substituting the regional usage error $v\left(\hat{q}_{i j}^{R}\right)$ and integrating over the unobservable $v_{i}^{L}$ to obtain the household's contribution to the log-likelihood:

$$
\ln \left[l_{i}\left(\Theta \mid d_{i}, q_{i j}^{L}, \hat{q}_{i j}^{R}, X_{i}\right)\right]=\sum_{j=1}^{J} I_{d_{i j}} \ln \left\{\int_{-\infty}^{\infty} f\left(d_{i j} \mid q_{i j}^{L}\left(v_{i}^{L}\right), \hat{q}_{i j}^{R}, X_{i} ; \Theta\right) d F v_{i}^{L}\right\} .
$$

We again use simulation techniques to approximate the integral in the likelihood.

(C) RAND 2008. 
FIGURE 3

\section{ILLUSTRATION OF COMPUTATION OF TRUNCATION MASS}

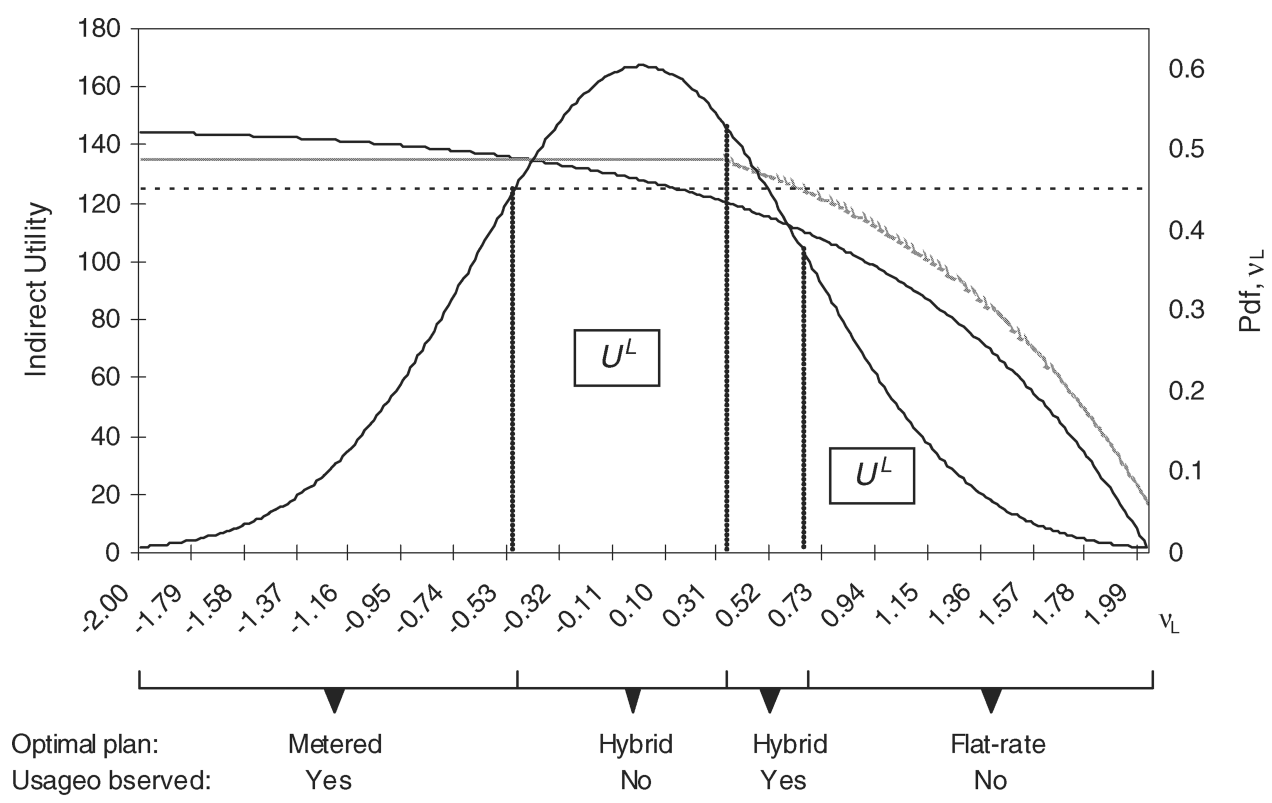

Ind.Utility,metered plan

Ind.Utility,hybrid plan ...... Ind.Utility,flat-rate plan

Identification. Both the discrete and the continuous choice equations identify parameters in our model. The parameters of the demand function, $a$ and $b$, are identified by variation in the observed usage and prices across space and time for households that have chosen a metered plan or consume above the allowance on a hybrid plan. The coefficients on $D_{i}$ are identified by systematic variation in usage for households with different characteristics, whereas the covariance parameters in $\Sigma_{v}$ are pinned down by remaining unexplained variance in usage quantities. These allow us to measure how well the observable characteristics explain households' plan choices and consumption. The parameter $b$ is identified by households with similar characteristics facing different per-call prices because they live in different places, consume on different plans, or consume at different times.

Variation in household and firm characteristics identify the parameters in the perceived firm quality index. The $\lambda$ parameters are identified by variation in characteristics of each provider's customers, relative to the base category, Verizon households. These different household/firm characteristics lead to different choices of firms' plans by households even at equivalent prices across the firms. The vector of $\xi$ parameters measures the common component of households' preferences in a particular firm/market and is identified by observing multiple households in the same market choosing the same firm.

$\square \quad$ Results. In estimation, we allow demand to shift as a function of the household's size, income, age category, and other communications services (cellular and Internet service) used by the household. We also include as a characteristic the plan's coverage area as a measure of the potential population a household can call given its location, as suggested by Taylor and Kridel (1990) and Bodnar, Dilworth, and Iacono (1988). The chosen utility function does not include income effects for either type of call, which are likely small given the average monthly bill is only $0.74 \%$ of the lowest income category. Instead, income is included as a proxy for intensity of use or the opportunity cost of time spent talking on the phone. Finally, we include a fourth-quarter dummy to allow for the possibility of increased usage during holiday periods. 
To capture differences in households' horizontal preferences for each carrier, we include the household's choice of one of the entrants' long-distance services, whether the household has recently moved to New York State, and the household's monthly income. To limit the number of parameters, we assume that customer service and other unobserved quality measures are constant within the metro and non-metro areas and estimate provider-specific fixed effects for these areas. We allow quality differences to vary by market structure by estimating separate fixed effects for the period prior to AT\&T's entry in November 1999, for the period of its limited rollout of service until August 2001, and for the remaining sample period after its entry into all of Verizon's territory. We normalize firm quality by setting the perceived quality of Verizon to zero.

Table 7 contains model estimates. Both local and regional usage are greater if the household owns a cellular phone. This suggests that cellular service proxies for intensity of household communication needs. Internet service is associated with significantly greater demand for local usage, consistent with most households accessing the Internet via phone lines during this time period. Usage of both services is also increasing in household size. The youngest cohort consumes the most of local service, but the least of regional service. Similarly, the middle age bracket has higher local, but lower regional, usage than the oldest cohort does. Higher-income households consume fewer local calls, but more regional calls than lower-income households do. Households make fewer regional calls, but not statistically different use of local calling, during the holiday period. Finally, the coverage area of a calling plan has the expected positive effect on regional usage, but a negative effect on local usage. This reflects perhaps other confounding factors such as a higher demand for local phone usage in rural areas with smaller coverage areas.

The results for the households' discrete choice differ from the earlier multinomial logit results, reflecting the effect of the usage decision on the plan choice captured by the full model. The quality dummies for AT\&T and MCI are negative, consistent with Verizon's greater market share. Unobserved AT\&T quality is greater in non-metro than metro regions, whereas unobserved MCI quality is greater in the later relative to the earlier period. Households that moved within the previous year are more likely to switch to AT\&T or MCI, whereas higher-income households are less likely to do so. Finally, households that have AT\&T as their long-distance provider are most likely to use AT\&T for local service and least likely to subscribe to Verizon. Households that have MCI for their long-distance service are most likely to use MCI for their local service, but then prefer Verizon to AT\&T, although the latter difference is not significant.

We recognize the nonlinear nature of the pricing plans in calculations of elasticities by estimating both a usage and a choice elasticity. We compute usage elasticities for both local and regional usage. Relative to previous studies of U.S. telecommunications services (for example, Train, McFadden, and Ben-Akiva, 1987; Danaher, 2002), we find a slightly more elastic industry demand for local usage $(-2.08)$, whereas demand for regional usage is less elastic $(-1.15)$ than it is for local. Our model allows us to estimate choice elasticities with respect to prices in a way that fully reflects the discrete/continuous nature of the consumers' choices. This is critical in computing elasticities in markets characterized by competition in menus of nonlinear pricing plans. For metered plans, we calculate the percentage response in market share to a percentage change in the fixed fee and local per-call price for each carrier. ${ }^{11}$ For both prices, AT\&T's residual demand is most elastic. Elasticities for Verizon's metered plans are least elastic for both the per-call price and the fixed fee. This results from the fact that many households (those located in New York City) do not have a Verizon flat-rate plan available as a choice, and if they have a strong preference for Verizon, have relatively inelastic demand for the one Verizon product available to them. Similar to the metered plan elasticities, we find an inelastic demand for Verizon's flat-rate plan in response to changes in the fixed fee.

$\square \quad$ Consumer welfare gains from entry. Our model allows us to perform various counterfactuals based on the estimated parameters. To assess the welfare implications of restricting the

\footnotetext{
${ }^{11}$ We weigh the choice responses by households' predicted choice probabilities.
} 


\begin{tabular}{|c|c|c|c|c|}
\hline \multirow[b]{2}{*}{ Variable } & \multicolumn{2}{|c|}{ Local Usage } & \multicolumn{2}{|c|}{ Regional Usage } \\
\hline & Coefficient & Standard Error & Coefficient & Standard Error \\
\hline \multicolumn{5}{|l|}{ Demand intercept $\left(a^{T}\right)$} \\
\hline CONSTANT $\left(\alpha^{T}\right)$ & $4.9146^{* * *}$ & 0.0266 & $1.3623^{* * *}$ & 0.0866 \\
\hline $\operatorname{INCOME}\left(\alpha_{D, 1}^{T}\right)$ & $-0.0243^{* * *}$ & 0.0027 & $0.0194^{* * *}$ & 0.0071 \\
\hline INTERNET $\left(\alpha_{D, 2}^{T}\right)$ & $0.1600^{* * *}$ & 0.0185 & $-0.1064^{* *}$ & 0.0504 \\
\hline $\operatorname{CELLULAR}\left(\alpha_{D, 3}^{T}\right)$ & $0.0265^{* *}$ & 0.0147 & $0.3031^{* * *}$ & 0.0499 \\
\hline $\operatorname{HHSIZE}\left(\alpha_{D, 4}^{T}\right)$ & $0.1203^{* * *}$ & 0.0098 & $0.1504^{* * *}$ & 0.0232 \\
\hline $\operatorname{AGE}(15-34)\left(\alpha_{D, 5}^{T}\right)$ & $0.1604^{* * *}$ & 0.0250 & $-0.6090^{* * *}$ & 0.0950 \\
\hline $\operatorname{AGE}(35-54)\left(\alpha_{D, 6}^{T}\right)$ & $0.0704^{* * *}$ & 0.0146 & $-0.4540^{* * *}$ & 0.0576 \\
\hline 4th QUARTER $\left(\alpha_{D, 7}^{T}\right)$ & 0.0042 & 0.0141 & $-0.2462^{* * *}$ & 0.0544 \\
\hline COVERAGE $\left(\alpha_{D, 8}^{T}\right)$ & $-0.0206^{* * *}$ & 0.0025 & $0.3494^{* * *}$ & 0.0714 \\
\hline Demand slope $\left(b^{T}\right)$ & $506.8994^{* * *}$ & 16.0700 & $9.7873^{* * *}$ & 0.7019 \\
\hline Standard deviation of $v^{T}\left(\sigma^{T}\right)$ & $0.4725^{* * *}$ & 0.0167 & $1.2081^{* * *}$ & 0.0312 \\
\hline Correlation, $v^{L}$ and $v^{R}$ & $-0.2213^{* * *}$ & 0.0655 & & \\
\hline Average usage price elasticity & \multicolumn{2}{|c|}{-2.08} & \multicolumn{2}{|c|}{-1.15} \\
\hline \multicolumn{5}{|c|}{ Discrete Choice } \\
\hline & Coefficient & Standard Error & & \\
\hline \multicolumn{5}{|l|}{ Choice $=\mathrm{AT} \& \mathrm{~T}$} \\
\hline $\operatorname{MOVED1Y}\left(\lambda_{11}\right)$ & $1.2183^{* * *}$ & 0.2996 & & \\
\hline $\operatorname{INCOME}\left(\lambda_{12}\right)$ & $-0.2154^{* * *}$ & 0.0238 & & \\
\hline $\operatorname{ATTLD}\left(\lambda_{13}\right)$ & $9.3138^{* * *}$ & 0.2837 & & \\
\hline $\operatorname{MCILD}\left(\lambda_{14}\right)$ & -0.0849 & 0.3121 & & \\
\hline$\xi_{\text {ATT }\left(1^{s t} W A V E / M E T R O\right)}$ & $-11.3126^{* * *}$ & 0.3083 & & \\
\hline$\xi_{A T T\left(1{ }^{s t} W A V E / N O N-M E T R O\right)}$ & -0.3235 & 0.2777 & & \\
\hline$\xi_{A T T\left(2^{\text {nd }} \text { WAVE } / M E T R O\right)}$ & $-8.5298^{* * *}$ & 0.3072 & & \\
\hline$\xi_{\text {ATT }\left(2^{n d} \text { WAVE } / N O N-M E T R O\right)}$ & $-4.3078^{* * *}$ & 0.2654 & & \\
\hline \multicolumn{5}{|l|}{ Choice $=$ MCI } \\
\hline $\operatorname{MOVED1Y}\left(\lambda_{21}\right)$ & $0.5976^{*}$ & 0.4199 & & \\
\hline $\operatorname{INCOME}\left(\lambda_{22}\right)$ & $-0.1358^{* * *}$ & 0.0217 & & \\
\hline $\operatorname{ATTLD}\left(\lambda_{23}\right)$ & $1.0200^{* * *}$ & 0.4048 & & \\
\hline $\operatorname{MCILD}\left(\lambda_{24}\right)$ & $5.2297^{* * *}$ & 0.3691 & & \\
\hline$\xi_{\text {MCI }\left(P R E / \text { Ist }_{\text {WAVE } / M E T R O}\right)}$ & $-5.6816^{* * *}$ & 0.3218 & & \\
\hline$\xi_{M C I\left(P R E / \text { Ist }_{\text {WAVE }} / N O N-M E T R O\right)}$ & $-8.9514^{* * *}$ & 0.4038 & & \\
\hline$\xi_{M C I\left(2^{n d} \text { WAVE } / M E T R O\right)}$ & $-4.5449^{* * *}$ & 0.3469 & & \\
\hline$\xi_{M C I\left(2^{\text {nd }} \text { WAVE } / N O N-M E T R O\right)}$ & $-3.9957^{* * *}$ & 0.3842 & & \\
\hline Choice elasticity with respect to & AT\&T & MCI & Verizon & \\
\hline Local usage price, metered plans & -1.8168 & -1.6263 & -0.7088 & \\
\hline Fixed-fee, metered plans & -2.5730 & -2.2339 & -0.6254 & \\
\hline Fixed-fee, flat-rate plans & -4.2365 & -4.9007 & -1.9151 & \\
\hline Log-likelihood & & $-34,378.80$ & & \\
\hline
\end{tabular}

The number of observations are 4791 for the discrete choice, 2876 for local usage, and 4672 for regional usage. Dummy variables are included to control for missing data for the CELLULAR and MOVED1Y variables. Choice elasticity weights households by likelihood of choosing carrier's plan.

* Significant at the $10 \%$ level.

** Significant at the $5 \%$ level.

${ }^{* * *}$ Significant at the $1 \%$ level.

available carriers to Verizon only, we compute the expected consumer surplus that households achieve by choosing the optimal contemporaneous plan available from Verizon and compare it to the expected consumer surplus obtained from choosing the optimal plan under the full range of choices. ${ }^{12}$ Estimates of the consumer welfare gains from entry under this counterfactual are

\footnotetext{
${ }^{12}$ We compute the expected consumer surplus using the "log-sum" formula derived in Small and Rosen (1981). We simulate over the usage unobservables holding each household's set of simulation draws fixed (if we do not observe usage) or fixed at the realized unobserved unobservable (if we observe usage) across all counterfactual analyses.
} 
TABLE 8 Monthly Consumer Welfare Gains in Monetary Equivalent Terms (\$): Counterfactual Analyses

\begin{tabular}{|c|c|c|c|c|c|c|}
\hline \multirow[b]{3}{*}{ Overall gains from entry } & \multicolumn{6}{|c|}{$\begin{array}{l}\text { Average Welfare Gain in } \$ \text { and as } \% \text { of Average Bill } \\
\text { (Standard deviation of welfare gain in } \$ \text { ) }\end{array}$} \\
\hline & \multicolumn{2}{|c|}{ All Households } & \multicolumn{2}{|c|}{ AT\&T Households } & \multicolumn{2}{|c|}{ MCI Households } \\
\hline & $\begin{array}{c}0.828 \\
(3.415)\end{array}$ & $2.50 \%$ & $\begin{array}{c}2.774 \\
(4.578)\end{array}$ & $7.09 \%$ & $\begin{array}{c}1.129 \\
(1.924)\end{array}$ & $3.66 \%$ \\
\hline Bundled local and regional plan ${ }^{\mathrm{b}}$ & $\begin{array}{c}0.211 \\
(1.887)\end{array}$ & $0.64 \%$ & $\begin{array}{c}0.661 \\
(2.667)\end{array}$ & $1.69 \%$ & & \\
\hline New York City flat-rate plans ${ }^{c}$ & $\begin{array}{c}0.681 \\
(3.989)\end{array}$ & $2.05 \%$ & $\begin{array}{l}2.215 \\
(6.267)\end{array}$ & $5.66 \%$ & $\begin{array}{c}0.807 \\
(1.771)\end{array}$ & $2.61 \%$ \\
\hline Service differentiation & $\begin{array}{c}0.256 \\
(1.092)\end{array}$ & $0.77 \%$ & $\begin{array}{l}1.837 \\
(2.246)\end{array}$ & $4.69 \%$ & $\begin{array}{c}0.643 \\
(2.105)\end{array}$ & $2.08 \%$ \\
\hline
\end{tabular}

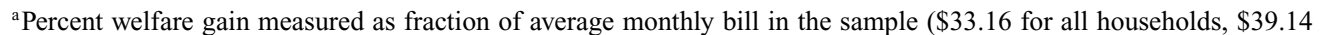
for AT\&T households, and \$30.87 for MCI households). The "All Households" category includes households on AT\&T, $\mathrm{MCI}$, and Verizon.

${ }^{\mathrm{b}}$ Only applicable to AT\&T households.

${ }^{\mathrm{c}}$ For households located in New York City.
}

displayed in the first row of Table 8 . In terms of the compensating variation, we find that across all households, the entry of AT\&T and MCI results in monetary savings of approximately $\$ 0.83$ or $2.5 \%$ of households' average monthly bill. The welfare gains across households vary significantly, however, with a standard deviation of $\$ 3.42$ in monetary savings. The large standard deviation results from most households achieving moderate benefits but a few realizing large benefits. We also split up welfare gains by entrant. AT\&T households gain more than MCI households do, with gains of $\$ 2.77$ and $\$ 1.13$ per household, respectively.

In addition to having additional choices of carriers, households also experience new pricing plan types offered by the entrants. Two important cases of plan introductions are the bundled local and regional service plan offered by AT\&T throughout its coverage area and the flat-rate plans introduced by AT\&T and MCI in New York City. Verizon, in contrast, does not introduce new plans in response to competition during the sample period. To quantify the benefits of these new plan types, we remove these plans from the households' choice sets and compare the expected consumer surplus obtained under this restricted set of options to the baseline. The difference estimates the monetary equivalent of the welfare gain from the introduction of these plans. Row 2 of Table 8 provides the estimates of the effects of the introduction of AT\&T's bundled plan. The average savings from the plan introduction across all households is $\$ 0.21$ with a standard deviation of $\$ 1.89$. Welfare gains from the other major new plan type, flat-rate plans in New York City, are listed in the third row of Table 8. Gains from these plans, $\$ 0.68$ on average across New York City households, are greater per-capita than from the bundled local and regional calling plan but accrue to only $17.7 \%$ of sample households. If averaged across all households, the benefits of the New York City flat-rate plans are $\$ 0.12$. Both plan introductions thus yield substantial contributions to the overall welfare gain, highlighting the importance of increased plan variety as a result of entry. AT\&T's and MCI's plan introductions alter the nature of price discrimination in these markets by using new nonlinear pricing or bundling strategies, which we find to be consumer welfare enhancing.

Our earlier descriptive results pointed to consumers regarding the providers' offerings as differentiated. We estimate the gains from this differentiation by allowing households to choose among the full range of plans, but eliminating any horizontal or vertical quality differences between firms. We do this by equating the $\zeta$ 's for the entrants to that of the incumbent (i.e., we set $\zeta_{i f}=0$ for all plans). Utility differences relative to the baseline expected consumer surplus quantify the differentiation effects from entry. The counterfactual as well as the estimation assumes that Verizon's service quality is constant during the sample period because we have no direct or anecdotal evidence that Verizon significantly improved customer service or increased advertising after entry. The last row of Table 8 summarizes estimates of these effects. We find 
TABLE 9 Stratified: Average Monthly Welfare Gain in \$ and as \% of Bill

\begin{tabular}{|c|c|c|c|c|c|c|c|}
\hline & \multicolumn{3}{|l|}{ Low } & \multicolumn{4}{|c|}{ High } \\
\hline & $\begin{array}{c}\text { Mean } \\
\text { (Standard deviation) }\end{array}$ & $\begin{array}{l}\% \text { of } \\
\text { Bill }\end{array}$ & $N$ & $\begin{array}{c}\text { Mean } \\
\text { (Standard deviation) }\end{array}$ & $\begin{array}{l}\% \text { of } \\
\text { Bill }\end{array}$ & $N$ & t-statistic ${ }^{a}$ \\
\hline Local usage ${ }^{\mathrm{b}}$ & $\begin{array}{c}0.293 \\
(1.543)\end{array}$ & $2.25 \%$ & 2419 & $\begin{array}{c}1.354 \\
(4.503)\end{array}$ & $6.18 \%$ & 2436 & -10.962 \\
\hline Use of vertical features ${ }^{c}$ & $\begin{array}{c}0.571 \\
(2.592)\end{array}$ & $3.91 \%$ & 3021 & $\begin{array}{c}1.244 \\
(4.413)\end{array}$ & $4.15 \%$ & 1834 & -6.696 \\
\hline Use of communications services ${ }^{\mathrm{d}}$ & $\begin{array}{c}0.741 \\
(2.512)\end{array}$ & $3.03 \%$ & 656 & $\begin{array}{c}1.458 \\
(4.866)\end{array}$ & $4.00 \%$ & 1403 & -3.560 \\
\hline \multicolumn{8}{|l|}{ Demand intercept, $E\left[a_{i}^{L}\right]^{\mathrm{e}}$} \\
\hline New York City hhs & $\begin{array}{c}0.986 \\
(2.976)\end{array}$ & $4.41 \%$ & 587 & $\begin{array}{c}4.136 \\
(8.540)\end{array}$ & $9.74 \%$ & 260 & -7.923 \\
\hline Remaining hhs & $\begin{array}{c}0.470 \\
(2.144)\end{array}$ & $2.88 \%$ & 1843 & $\begin{array}{c}0.687 \\
(3.102)\end{array}$ & $3.91 \%$ & 2165 & -2.531 \\
\hline $\begin{array}{l}\text { Use of carrier across } \\
\text { services }^{f}\end{array}$ & $\begin{array}{c}0.522 \\
(3.142)\end{array}$ & $2.10 \%$ & 4136 & $\begin{array}{c}2.569 \\
(4.276)\end{array}$ & $10.53 \%$ & 719 & -15.200 \\
\hline
\end{tabular}

${ }^{\mathrm{a}}$ T-test statistic for $\mu_{\text {low }}-\mu_{\text {high }}$.

${ }^{\mathrm{b}}$ High local usage denotes households with above-median usage, including flat-rate households.

${ }^{c}$ High usage of vertical features denotes households with positive vertical features expenditures.

${ }^{\mathrm{d}}$ High usage of communications services denotes households that use at least one of cellular service, Internet, pager, fax, or a personal digital assistant (PDA).

${ }^{\mathrm{e}}$ High demand intercept denotes households with an above-median predicted demand intercept.

${ }^{\mathrm{f}} \mathrm{High}$ use of carrier across services denotes households that also use their local carrier for long-distance service; low use denotes households that do not.

that on average households gain $\$ 0.26$ in monetary savings $(0.77 \%$ of the average monthly bill) from firm heterogeneity, with a standard deviation of $\$ 1.09$. AT\&T households benefit most from differentiation ( $\$ 1.84$ per household on average) relative to MCI households $(\$ 0.64$ per household).

We next investigate the extent to which heterogeneity in welfare gains is correlated with household observables. First, we consider welfare gains as a function of the households' valuation of telephone service using several observed proxies for valuation of telephone service. These include the intensity of usage measured in terms of calls made or the predicted local demand intercept, the use of vertical features, and the use of additional communication services (Internet, cellular, or paging services). Table 9 displays summary statistics of welfare gains for high- and low-valuation households. Across all proxies for valuation, high-valuation households realize statistically significant higher welfare gains in monetary terms. However, as a percent of their monthly bill, only usage-intensive households benefit significantly more, both in a statistical and in an economic sense, from entry. New York City households benefit more than other households do, using the household's predicted local demand intercept as a proxy for usage intensity. As a result, low-usage households in New York City benefit by about the same amount as high-usage households outside of New York City. In Table 9, we also compare households that benefit from bundling of local and long-distance services (and therefore single-billing) by the entrants to the remaining households. In a confirmation of the descriptive results, we find that gains for households that use an entrant for both services outweigh gains of the remaining households by a factor of five.

The results in Table 10, which explain the monetary welfare benefits by the household characteristics in a tobit model, reinforce and extend these findings. The welfare gains increase by $\$ 0.22$ and $\$ 1.95$ for each additional household member for households outside and inside New York City, respectively. Welfare is higher by $\$ 1.20$ for black households and decline by a modest $\$ 0.12$ for every additional $\$ 1000$ of monthly income. Because larger, lower-income households have higher local telecommunications services demand, on average, entry benefits 
TABLE 10 Tobit Estimates of Amount of Welfare Gain

\begin{tabular}{|c|c|c|}
\hline & Coefficient & Standard Error \\
\hline INTERNET & 0.4218 & 0.2982 \\
\hline CELLULAR & 0.3499 & 0.2873 \\
\hline NYCITY & $-1.4622^{* *}$ & 0.7005 \\
\hline HHSIZE & 0.2212 & 0.1398 \\
\hline NYCITY*HHSIZE & $1.7311^{* * *}$ & 0.2801 \\
\hline INCOME & $-0.1153^{* *}$ & 0.0454 \\
\hline AGE (15-34) & 0.8252 & 0.5059 \\
\hline AGE (35-54) & -0.0326 & 0.3191 \\
\hline MOVED1Y & 0.6709 & 0.7505 \\
\hline DMOVED & -0.1151 & 0.8138 \\
\hline BLACK & $1.2017^{* *}$ & 0.5157 \\
\hline HISPANIC & -0.7172 & 0.7158 \\
\hline RACEO & 0.5678 & 0.7071 \\
\hline ATTLD & $3.1055^{* * *}$ & 0.4402 \\
\hline MCILD & $1.2628^{* *}$ & 0.4942 \\
\hline$\sigma$ & $3.7111^{* * *}$ & 0.0931 \\
\hline $\mathrm{N}$ & \multicolumn{2}{|c|}{810} \\
\hline Log-likelihood & \multicolumn{2}{|c|}{-2184.01} \\
\hline Likelihood ratio index & \multicolumn{2}{|c|}{0.04} \\
\hline$\%$ uncensored observations & \multicolumn{2}{|c|}{0.98} \\
\hline
\end{tabular}

${ }^{*}$ Significant at $10 \%$.

** Significant at $5 \%$.

${ }^{* * *}$ Significant at $1 \%$.

disproportionately high-usage, and thus high-valuation, households. This combined with the results in Table 9 suggests that entry intensified competition for high-valuation customers. As in Table 9, the most significant source of gains is the ability to use a single provider for both services, associated with an increase in welfare gains by $\$ 3.11$ and $\$ 1.26$ for AT\&T and MCI households, respectively.

As a last counterfactual analysis, we investigate the benefits generated from discounts available to qualifying low-income households. AT\&T and MCI offered discounts on the monthly fixed fee for flat-rate plans, while Verizon offered them on flat-rate and metered plans. In our sample, $13.2 \%$ of households pay the discounted rates. Removing the discounted plans from qualifying households' choice sets suggests that they benefit by on average $\$ 5.18$, or $13.2 \%$, from their availability (averaged over all households, the benefits are $\$ 0.69$, or $1.75 \%$ ). These figures represent an upper bound on consumer benefits, however, as our model precludes the households from disconnecting their service altogether in response to an elimination of low-income discounts. We also do not account for the additional waiver of a subscriber line charge for $\$ 6.50$ that the households receive, which increases consumer benefits.

We conduct several robustness checks to investigate the sensitivity of our results and the accompanying welfare effects to our modelling assumptions. First, we investigate further the importance of inertia, switching costs, and consumer learning about the entrants' services and their own level of demand. These factors would introduce state-dependence into consumer behavior that we abstract from in our model. We reestimate the model using data from the second half of the sample period only (Q1 2002 to Q1 2003), a period when consumer learning is arguably likely to have already occurred. The estimated coefficients based on this subsample of households imply average welfare effects of $\$ 1.08$ per household, which is slightly higher, but similar to that of the full sample. ${ }^{13}$ Second, as discussed in Section 3, we lose a number of observations due to

\footnotetext{
${ }^{13}$ Using data after the introduction of metered service, Narayanan, Chintagunta, and Miravete (2007) find modest welfare effects of consumers resolving uncertainty primarily about average usage, which the households did not observe previously. In our setting, uncertainty about mean usage is likely significantly smaller.
} 
data incompleteness and data entry errors. The degree of attrition in the data at the carrier level is $15 \%$ for AT\&T, $38 \%$ for MCI, and $24 \%$ for Verizon. We reestimate the model adjusting the likelihood for the differential attrition rates at the carrier level. We find the model estimates to be robust to this alternative likelihood specification.

Because our data are of limited duration, we focus on the medium-term effects of unbundling. In the long term, unbundling may influence the incentives of incumbents and entrants to invest in infrastructure. One of the goals of the 1996 Act is to encourage the rapid deployment of new telecommunications technologies. The literature has debated whether it provides the correct incentive structure for incumbents and entrants to do so (see Hausman and Sidak, 2005, for a summary of the issues in question and Crandall, Ingraham, and Singer, 2004, for some empirical evidence on the effect of lease rates on incumbents' investment). Avenues for unbundling to contribute to such deployment include allowing entrants to invest profits earned through accessbased entry in their own infrastructure and inducing incumbents to increase investments in the more competitive market. At the same time, fear that the new investments would be subject to unbundling might deter such investment. However, such fears have not been realized thus far in the United States, where regulators have not ordered any unbundling at cost-based prices after the 1996 Act and new fiber-to-the-home networks by AT\&T and Verizon are essentially unregulated.

\section{Conclusion}

- A major goal of the 1996 Telecommunications Act was to encourage entry into local phone service with the objectives of achieving better alignment between prices and costs, increased service quality, increased variety of service offerings, and efficiency gains in the form of "onestop shopping" across different telecommunications services. In this article, we develop a model to measure the realization of these goals by evaluating consumer welfare gains in each of these areas. We quantify total welfare effects and estimate the contributions from pure price effects, horizontal and vertical quality differences across providers, and new pricing plan introductions, using a random sample of households in New York State.

Our counterfactual analyses suggest that the average household in the sample benefited by $2.5 \%$ of the average monthly bill in total from the additional plan and provider choices introduced by the entrants. Our results show that although households benefit from price reductions due to AT\&T's and MCI's entry into local phone service, they benefit more from the entrants' new plan types and quality differences from the incumbent's services. Our work suggests that regulators take into account more than price effects in considering whether to unbundle networks and in evaluating the numerous unbundling experiments taking place around the world. This is of particular relevance for recent years where cellular and Internet phone companies have competed more effectively with local telephone companies for subscribers. By 2006, an estimated $12.8 \%$ of U.S. households rely solely on cellular phones for communication, while $3.1 \%$ use Internet phone service via Voice over Internet Protocol (Blumberg, Luke, and Cynamon, 2006). The consumer welfare gains from the increased viability of such services as full substitutes for local phone service likely exceed our estimated welfare gains substantially, due to both increased product variety and increased price competition.

Although the United States effectively discontinued unbundling of local service in 2004, before an evaluation of its longer-term welfare effects became possible, some of the worldwide examples of unbundling may yield longer time series of data to permit such an evaluation. Interesting extensions to our current results include evaluating whether consumers choose to remain with or continue to switch to entrants' services in the longer term and whether entrants' service differentiation persists or consumers perceive providers' services as more homogeneous over time. Other contexts also raise different regulatory issues related to unbundling. For example, under the European Union's 2000 Unbundling Regulations, national regulators may decide to set lease rates for combined unbundling of voice and data service as well as for limited unbundling 
of data access only. Our econometric model can easily accommodate consumers' choices to purchase voice and data service from the same or from different firms to estimate the welfare effects of alternative pricing scenarios for full unbundling relative to unbundling of data service only.

\section{Appendix A}

- In this appendix, we derive the feasible set for local usage for a household that chooses plan $j$. The derivation of constraints on regional usage is analogous. To derive a constraint on local usage for household $i$ that prefers plan $j$ to plan $k$, we first find the range of $v_{i}^{L}$ for which plan $j$ is preferred to plan $k$ conditional on the unobserved plan preferences $\epsilon_{i j}$ and $\epsilon_{i k}$ and the regional usage unobservable $v_{i}^{R}$. Household $i$ chooses plan $j$ over plan $k$ when the indirect utility from plan $j$ exceeds that from plan $k$ (i.e., $v_{i j}>v_{i k}$ ). Using the indirect utility function (equation (5)) conditional on a particular realization of $\epsilon_{i j}, \epsilon_{i k}$, and $v_{i}^{R}$, this leads to a cutoff $\bar{v}_{i j k}^{L}\left(v_{i}^{R}, X_{i}, \epsilon_{i} ; \Theta\right)$ such that

$$
\begin{aligned}
\exp \left[v_{i}^{L}\right]< & \frac{1}{\exp \left[\alpha^{L}+\alpha_{D}^{L} D_{i}\right]\left(p_{j}^{L}-p_{k}^{L}\right)}\left\{\left(P_{k}-P_{j}\right)+\Delta \zeta_{i}-\left(\epsilon_{i k}-\epsilon_{i j}\right)\right. \\
& \left.-\frac{b^{L}}{2}\left[\left(p_{k}^{L}\right)^{2}-\left(p_{j}^{L}\right)^{2}\right]-\frac{b^{R}}{2}\left[\left(p_{k}^{R}\right)^{2}-\left(p_{j}^{R}\right)^{2}\right]+\exp \left[\alpha^{R}+\alpha_{D}^{R} D_{i}+v_{i}^{R}\right]\left(p_{k}^{R}-p_{j}^{R}\right)\right\} \\
& \equiv \exp \left(\bar{v}_{i j k}^{L}\left(v_{i}^{R}, X_{i}, \epsilon_{i} ; \Theta\right)\right),
\end{aligned}
$$

if $p_{j}^{L}>p_{k}^{L}$. If $p_{j}^{L}<p_{k}^{L}$, then $\exp \left[v_{i}^{L}\right]>\exp \left(\bar{v}_{i j k}^{L}\left(v_{i}^{R}, X_{i}, \epsilon_{i} ; \Theta\right)\right)$. The cutoff on the local usage unobservable translates into a constraint on the observed usage of $\hat{q}_{i j}^{L}<\bar{q}_{i j k}^{L} \equiv \exp \left[\alpha^{L}+\alpha_{D}^{L} D_{i}+\bar{v}_{i j k}^{L}\left(v_{i}^{R}, X_{i}, \epsilon_{i} ; \Theta\right)\right]-b^{L} p_{j}^{L}$ if $p_{j}^{L}>p_{k}^{L}$ and $\hat{q}_{i j}^{L}>\bar{q}_{i j k}^{L}$ if $p_{j}^{L}<p_{k}^{L}$.

The set of unobserved plan preferences that ensure that this quantity constraint is satisfied results from substituting $\bar{v}_{i j k}^{L}\left(v_{i}^{R}, X_{i}, \epsilon_{i} ; \Theta\right)$ from equation (A1) into the quantity constraint and rearranging

$$
\begin{aligned}
\epsilon_{i j}-\epsilon_{i k}> & \hat{q}_{i j}^{L}\left(p_{j}^{L}-p_{k}^{L}\right)+\left(P_{j}-P_{k}\right)-\Delta \zeta_{i}-\frac{b^{L}}{2}\left[\left(p_{j}^{L}\right)^{2}-\left(p_{k}^{L}\right)^{2}\right] \\
& -\frac{b^{R}}{2}\left[\left(p_{j}^{R}\right)^{2}-\left(p_{k}^{R}\right)^{2}\right]+\exp \left[\alpha^{R}+\alpha_{D}^{R} D_{i}+v_{i}^{R}\right]\left(p_{j}^{R}-p_{k}^{R}\right)+b^{L} p_{j}^{L}\left(p_{j}^{L}-p_{k}^{L}\right) \\
& \equiv \bar{m}_{i j k}^{L}\left(v_{i}^{R}, X_{i} ; \Theta\right),
\end{aligned}
$$

which is equation (14) in the article. If plan $j$ is a hybrid plan, we observe usage only for households that exceed the allowance. In this case, equation (A2) becomes

$$
\begin{aligned}
\epsilon_{i j}-\epsilon_{i k}> & \hat{q}_{i j}^{L}\left(\tilde{p}_{j}^{L}-p_{k}^{L}\right)+\left(P_{j}-P_{k}\right)-\Delta \zeta_{i}-\tilde{p}_{j}^{L} \tilde{q}_{j}^{L}-\frac{b^{L}}{2}\left[\left(\tilde{p}_{j}^{L}\right)^{2}-\left(p_{k}^{L}\right)^{2}\right] \\
& -\frac{b^{R}}{2}\left[\left(p_{j}^{R}\right)^{2}-\left(p_{k}^{R}\right)^{2}\right]+\exp \left[\alpha^{R}+\alpha_{D}^{R} D_{i}+v_{i}^{R}\right]\left(p_{j}^{R}-p_{k}^{R}\right)+b^{L} \tilde{p}_{j}^{L}\left(\tilde{p}_{j}^{L}-p_{k}^{L}\right) .
\end{aligned}
$$

If the comparison plan $k$ is a hybrid plan, we use as our cutoff on the unobserved preferences the larger of (i) the cutoff that results from using the indirect utility on plan $k$ for usage above the allowance and (ii) that from using the indirect utility on plan $k$ for usage below the allowance.

\section{Appendix B}

- This appendix contains a detailed outline of the estimation algorithm. The estimation procedure works as follows:

(i) For each household with quantity data, draw a matrix of $N_{1}\left(J_{i}-1\right)$-dimensional errors from a logistic distribution, where $J_{i}$ is the number of plans available to household $i$. These represent $\epsilon_{i}$ differences between one plan in the choice set and the remaining $\left(J_{i}-1\right)$ plans, which are sufficient to build the $\epsilon_{i}$ difference for any two plans in the household's choice set. ${ }^{14}$ To draw the logistic errors subject to the truncation points described by equations (A2) and (A3), we follow Train (2002). We set $N_{1}$ equal to 30 and hold these draws constant for the remainder of the algorithm.

(ii) For each household with missing local quantity data, draw a vector of $N_{2}$ errors from a bivariate normal distribution, representing $v_{i}^{L}$ and $v_{i}^{R}$, which are held constant through all iterations of the estimation routine. We set $N_{2}$ equal to 30 and hold these draws constant for the remainder of the algorithm.

${ }^{14}$ The relationship between drawing from a logistic distribution and differences in type-1 extreme value errors is explained in Train (2002). 
(iii) For households with observed local and regional quantity information:

Step 1. Compute the predicted demand shocks at the current parameter estimates:

(a) Back out the household's realization of $v_{i}^{L}$ and $v_{i}^{R}$ at the observed quantity choices $\hat{q}_{i j}^{L}$ and $\hat{q}_{i j}^{R}$ using equation (9).

(b) Determine the household's optimal local and regional quantities on each plan based on $v\left(\hat{q}_{i j}^{L}\right)$ and $v\left(\hat{q}_{i j}^{R}\right)$. For all metered and flat-rate plans, use equations (3) and (4) to compute the optimal quantity. For hybrid plans, compute the optimal usage on the plan based on equation (3), using $\tilde{p}_{j m}$. If the optimal quantity is below the threshold, then compute the optimal quantity based on a zero per-unit price (equation (4)). If the optimal quantity based on a zero per-unit price is above $\tilde{q}_{j}$, then set usage to $\tilde{q}_{j}$.

Step 2. Based on the optimal local and regional quantities, compute the plan-choice probabilities at the current parameter estimates:

(a) Compute the deterministic part of each plan's indirect utility using the appropriate indirect utility function from equations (5) and (6).

(b) Compute $f\left(d_{i j}\right)$ according to equation (15) conditional on $v\left(\hat{q}_{i j}^{L}\right)$ and $v\left(\hat{q}_{i j}^{R}\right)$.

Step 3. Determine the optimal plan over the entire support of $v^{L}$. Partition the $v^{L}$ support into $S$ segments such that plan $s$ is optimal over segment $s$, conditional on the current set of parameters, unobservable plan-specific preferences, and the household's optimal regional usage on plan $s$ (based on $v\left(\hat{q}_{i j}^{R}\right)$ implied by the chosen plan $j$ ). ${ }^{15}$ We denote the segments' end points by $\bar{v}_{i}^{1}, \bar{v}_{i}^{2}, \ldots, \bar{v}_{i}^{S+1}$ and compute them as follows:

(a) Truncate each draw of $\epsilon_{i}^{n}$ to be consistent with equation (14).

(b) Given the truncated $\epsilon_{i}^{n}$ 's, eliminate all flat-rate plans except the optimal one based on equations (5) and (6). Also, eliminate any other plans that are dominated by another single plan or combination of plans.

(c) The initial and final segments in the tails of the distribution are defined over $v_{i}^{L} \in\left[\bar{v}_{i}^{1}, \bar{v}_{i}^{2}\right]$ and $v_{i}^{L} \in\left[\bar{v}_{i}^{S}, \bar{v}_{i}^{S+1}\right]$, where $\bar{v}_{i}^{1}=-\infty$ and $\bar{v}_{i}^{S+1}=\infty$. In practice, we set $\bar{v}_{i}^{1}=-5 \sigma^{L}$ and $\bar{v}_{i}^{S+1}=5 \sigma^{L}$.

(d) Identify the plan that provides the highest indirect utility at $v_{i}^{L}=\bar{v}_{i}^{1}$ :

(i) For each plan, compute the optimal quantity and the corresponding indirect utilities from equations (5) and (6) given $\bar{v}_{i}^{1}$.

(ii) Find the plan $g$ that provides the maximum indirect utility, index it by $s=1$, and remove it from the consideration set.

(e) Find $\bar{v}_{i}^{s}, s=2,3, \cdots, S-1, S$ :

(i) Compute the $v_{i}^{L}$ for which household $i$ is indifferent between plan $g$ and each of the plans $k$ remaining in the consideration set. For each pair of plans, $g$ and $k$, this cutoff equals

$$
\begin{aligned}
\bar{v}_{i g k}= & \ln \left[\frac { 1 } { \operatorname { e x p } [ \alpha ^ { L } + \alpha _ { D } ^ { L } D _ { i } ] ( p _ { g } ^ { L } - p _ { k } ^ { L } ) } \left\{\left(P_{k}-P_{g}\right)+\Delta \zeta_{i}\right.\right. \\
& -\left(\epsilon_{i k}-\epsilon_{i g}\right)-\frac{b^{L}}{2}\left[\left(p_{k}^{L}\right)^{2}-\left(p_{g}^{L}\right)^{2}\right]-\frac{b^{R}}{2}\left[\left(p_{k}^{R}\right)^{2}-\left(p_{g}^{R}\right)^{2}\right] \\
& \left.\left.+\exp \left[\alpha^{R}+\alpha_{D}^{R} D_{i}+v_{i}^{R}\right]\left(p_{k}^{R}-p_{g}^{R}\right)\right\}\right] .
\end{aligned}
$$

If plan $g$ is a hybrid plan, we compute two separate cutoffs, one for $p_{g}^{L}=0$ and one for $p_{g}^{L}=\tilde{p}_{g}^{L}$, as discussed in Appendix A. We then verify that the resulting cutoffs $\bar{v}_{i g k}\left(p_{g}^{L}=0, p_{k}^{L}\right)$ and $\bar{v}_{i g k}\left(p_{g}^{L}=\right.$ $\left.\tilde{p}_{g}^{L}, p_{k}^{L}\right)$ entail usage that falls into the usage segment where the respective usage price applies, with $q_{i g}^{L}\left(\bar{v}_{i g k}\left(p_{g}^{L}=0, p_{k}^{L}\right)\right) \leq \widetilde{q}_{g}^{L}$ and $q_{i g}^{L}\left(\bar{v}_{i g k}\left(p_{g}^{L}=\widetilde{p}_{g}^{L}, p_{k}^{L}\right)\right)>\widetilde{q}_{g}^{L}$, and retain only those cutoffs that satisfy their quantity restriction. If both plans $g$ and $k$ are hybrid plans, we allow for the possibility of four separate cutoffs and verify quantity conditions on both plans, which again results in at most two cutoffs between the two plans.

(ii) Cutoff $\bar{v}_{i}^{s}$ is the minimum $\bar{v}_{i g k}$ for all $k$. Denote the associated plan by $g$ and index it by $s$. If there is at most one valid cutpoint between plan $g$ and each of the remaining plans greater than $\bar{v}_{i}^{s}$, remove plan $g$ from the consideration set as it will not be optimal for any $v_{i}^{L}>\bar{v}_{i}^{s}$. Repeat the previous step until all remaining plans in the consideration set have been assigned to a segment of $v_{i}^{L}$.

Step 4. Compute the probability mass corresponding to those segments among $S$ for which usage data would be unobserved:

(a) Determine over what portion of each segment, if any, we would not observe the local quantity:

(i) If plan $s$ is a flat-rate plan, we do not observe usage for any $v_{i}^{L} \in\left[\bar{v}_{i}^{s}, \bar{v}_{i}^{s+1}\right]$.

${ }^{15}$ Such a partition into consecutive ranges is possible because indirect utility declines monotonically in $v_{i}^{L}$. As a result, there is at most one $v_{i}^{L}$ where the indirect utilities on any pair of a flat-rate and a metered plan are equal and at most two for any pair of a hybrid and a metered plan or pair of two hybrid plans. 
(ii) If plan $s$ is a hybrid plan, we do not observe usage for the portion of $v_{i}^{L} \in\left[\bar{v}_{i}^{s}, \bar{v}_{i}^{s+1}\right]$ that entails usage below the allowance:

Compute the quantity of local calls at $\bar{\nu}_{i}^{s+1}$ at a usage price of zero

$$
q_{i s}^{L}\left(\bar{v}_{i}^{s+1}\right)=\exp \left(\alpha^{L}+\alpha_{D}^{L} D_{i}+\bar{v}_{i}^{s+1}\right) .
$$

If $q_{i s}^{L}\left(\bar{v}_{i}^{s+1}\right)>\tilde{q}_{s}$, then compute the $v_{i}^{L}$ in segment $s$ where household $i$ first exceeds the call allowance $\tilde{q}_{s}$ at the positive usage price $\tilde{p}_{s}^{L}$ as

$$
\tilde{v}_{i}^{s+1}=\ln \left(\tilde{q}_{s}+b^{L} \widetilde{p}_{s}^{L}\right)-\alpha^{L}-\alpha_{D}^{L} D_{i} .
$$

If $q_{i s}^{L}\left(\bar{v}_{i}^{s+1}\right) \leq \tilde{q}_{s}$, we do not observe usage for any $v_{i}^{L} \in\left[\bar{v}_{i}^{s}, \bar{v}_{i}^{s+1}\right]$ and $\tilde{v}_{i}^{s+1}=\bar{v}_{i}^{s+1}$.

(b) Denote by $U_{i}^{L n}$ the probability of $v_{i}^{L}$ falling into any of the segments without usage data

$$
U_{i}^{L n}=\sum_{s \in S}\left(I_{s}^{F}+I_{s}^{H}\right)\left(\Phi\left(\frac{I_{s}^{F} \bar{\nu}_{i}^{s+1}+I_{s}^{H} \tilde{v}_{i}^{s+1}}{\sigma_{L}}\right)-\Phi\left(\frac{\bar{v}_{i}^{s}}{\sigma_{L}}\right)\right),
$$

where $I_{s}^{F}$ is a flat-rate plan indicator and $I_{s}^{H}$ a hybrid plan indicator.

Repeat steps 3 and 4 for all $N_{1}$ truncated $\epsilon_{i}$ draws.

(iv) For households without local quantity information:

Step 1. Determine the household's optimal quantity on each plan for the $v_{i}^{L n}$ draw and the implied $v\left(\hat{q}_{i j}^{R}\right)$.

Step 2. Based on the optimal quantities, compute the predicted plan-choice probabilities:

(a) Compute the deterministic part of each plan's indirect utility using the appropriate indirect utility function from equations (5) and (6).

(b) Compute $f\left(d_{i j}\right)$ according to equation (15) conditional on the household's current draw $v_{i}^{L n}$.

Repeat steps 1 and 2 for all $N_{2} v$ draws.

(v) Compute the joint probability of plan and usage choices for each household and each plan: For households with observed local usage data, this joint probability equals

$$
\begin{aligned}
\ln \left[l_{i}\right]= & \sum_{j=1}^{J} I_{d_{i j}} \ln \left\{f\left(d_{i j} \mid v\left(\hat{q}_{i j}\right), X_{i} ; \Theta\right)\left(\frac{1}{1-\frac{1}{N_{1}} \sum_{n=1}^{N_{1}} U_{i}^{L n}}\right) \frac{1}{(2 \pi)^{1 / 2}\left|\Sigma_{v}\right|^{\frac{1}{2}}}\right. \\
& \left.\mathcal{J}_{i} \exp \left[\frac{-v\left(\hat{q}_{i j}\right)^{\prime} \Sigma_{v}^{-1} v\left(\hat{q}_{i j}\right)}{2}\right]\right\}
\end{aligned}
$$

if $\hat{q}_{i j}^{R}>0$, or

$$
\begin{aligned}
\ln \left[l_{i}\right]= & \sum_{j=1}^{J} I_{d_{i j}} \ln \left\{f\left(d_{i j} \mid v\left(\hat{q}_{i j}\right), X_{i} ; \Theta\right)\left(\frac{1}{1-\frac{1}{N_{1}} \sum_{n=1}^{N_{1}} U_{i}^{L n}}\right) \frac{\left(1-\Phi\left(v^{R}\left(\hat{q}_{i j}^{R}=0\right)\right)\right)}{\sqrt{2 \pi} \sigma_{L}}\right. \\
& \left.\mathcal{J}_{i} \exp \left[\frac{-\left(v^{L}\left(\hat{q}_{i j}^{L}\right)\right)^{2}}{2 \sigma_{L}^{2}}\right]\right\}
\end{aligned}
$$

if $\hat{q}_{i j}^{R}=0 . \Phi$ is the cdf of $v^{R}$ conditional on $v^{L}\left(\hat{q}_{i j}^{L}\right)$.

For households without local usage data, this probability equals their plan choice probability

$$
\ln \left[l_{i}\right]=\sum_{j=1}^{J} I_{d_{i j}} \ln \left\{\frac{1}{N_{2}} \sum_{n=1}^{N_{2}} f\left(d_{i j} \mid v\left(\hat{q}_{i j}^{R}\right), v_{i}^{L n}, X_{i} ; \Theta\right)\right\} .
$$

(vi) Update the parameters to maximize the log-likelihood function for the entire sample

$$
\ln \mathcal{L}\left(\Theta \mid d, \hat{q}^{L}, \hat{q}^{R}, X\right)=\sum_{i=1}^{I} \ln \left[l_{i}\left(\Theta \mid d_{i}, \hat{q}_{i j}^{L}, \hat{q}_{i j}^{R}, X_{i}\right)\right] .
$$

\section{References}

Berry, S. "Estimating Discrete Choice Models of Product Differentiation." RAND Journal of Economics, Vol. 25 (1994), pp. 242-262.

—, Levinsohn, J., And PaKes, A. “Automobile Prices in Market Equilibrium.” Econometrica, Vol. 64 (1995), pp. $841-890$.

"Differentiated Products Demand Systems from a Combination of Micro and Macro Data: The New Vehicle Market." Journal of Political Economy, Vol. 112 (2004), pp. 68-104. 
Blumberg, S., Luke, J., And Cynamon, M. "Telephone Coverage and Health Survey Estimates: Evaluating the Need for Concern about Wireless Substitution." American Journal of Public Health, Vol. 96 (2006), pp. 926931.

Bodnar, J., Dilworth, P., And Iacono, S. "Cross-section Analysis of Residential Telephone Subscription in Canada." Information Economics and Policy, Vol. 3 (1988), pp. 311-331.

Chan, T. "Demand for Soft Drinks: Characteristics, Corners, and Continuous Choice." RAND Journal of Economics, Vol. 37 (2006), pp. 466-482.

Chiang, J. "A Simultaneous Approach to the Whether, What and How Much to Buy Questions." Marketing Science, Vol. 10 (1991), pp. 297-315.

— AND LEE, L. "Discrete/Continuous Models of Consumer Demand with Binding Nonnegativity Constraints." Journal of Econometrics, Vol. 54 (1992), pp. 79-93.

CRANDALl, R. AND SidAK, J. "Is Structural Separation of Incumbent Local Exchange Carriers Necessary for Competition?" Yale Journal on Regulation, Vol. 19 (2002), pp. 1-75.

—, Ingraham, A., AND Singer, H. "Do Unbundling Policies Discourage CLEC Facilities-Based Investment?" Topics in Economic Analysis \& Policy, Vol. 4 (2004), pp. 1-23.

Danaher, P. "Optimal Pricing of New Subscription Services: Analysis of a Market Experiment." Marketing Science, Vol. 21 (2002), pp. 119-138.

DellaVigna, S. And Malmendier, U. "Paying Not to Go to the Gym." American Economic Review, Vol. 96 (2006), pp. 694-719.

Dubé, J. "Multiple Discreteness and Product Differentiation: Demand for Carbonated Soft Drinks." Marketing Science, Vol. 23 (2004), pp. 66-81.

Dubin, J. Consumer Durable Choice and the Demand for Electricity. Amsterdam: North-Holland, 1985. AND McFAdDEN, D. "An Economic Analysis of Residential Electric Appliance Holdings and Consumption." Econometrica, Vol. 52 (1984), pp. 345-362.

EConomides, N. "Telecommunications Regulation: An Introduction.” In R.R. Nelson, ed., The Limits and Complexity of Organizations. New York: Russell Sage Foundation, 2005.

Federal Communications Commission. "Local Telephone Competition: Status as of December 31, 2003." Industry Analysis and Technology Division, Wireline Competition Bureau, Federal Communications Division (2004).

Goolsbee, A. And Petrin, A. "The Consumer Gains from Direct Broadcast Satellites and the Competition with Cable TV." Econometrica, Vol. 72 (2004), pp. 351-381.

Greenstein, S. And Mazzeo, M. "The Role of Differentiation Strategy in Local Telecommunication Entry and Market Evolution: 1999-2002.” Journal of Industrial Economics, Vol. 54 (2006), pp. 323-350.

Hanemann, W. "Discrete/Continuous Models of Consumer Demand.” Econometrica, Vol. 52 (1984), pp. 541-561.

Hausman, J. AND SidAK, G. "Did Mandatory Unbundling Achieve Its Purpose? Empirical Evidence from Five Countries." Journal of Competition Law and Economics, Vol. 1 (2005), pp. 173-245.

—, TARdiff, T., AND Belinfante, A. "The Breaking Up of AT\&T and Changes in Telecommunications Regulation: What Are the Lessons?” American Economic Review, Vol. 83 (1993), pp. 178-184.

Hendel, I. "Estimating Multiple-Discrete Choice Models: An Application to Computerization Returns." Review of Economic Studies, Vol. 66 (1999), pp. 423-446.

Hobson, M. And Spady, R. “The Demand for Local Telephone Service under Optional Local Measured Service.” Bellcore Economics Discussion Paper 50 (1988).

Kim, J., Allenby, G., And Rossi, P. “Modeling Consumer Demand for Variety.” Marketing Science, Vol. 21 (2002), pp. 229-250.

Kling, J. AND VAN DER Ploeg, S. "Estimating Local Call Elasticities with a Model of Stochastic Class of Service and Usage Choice.” In A. De Fontenay, M. Shugard, and D. Sibley, eds., Telecommunications Demand Modeling: An Integrated View. Amsterdam: North-Holland, 1990.

Maddala, G. Limited-Dependent and Qualitative Variables in Econometrics. Cambridge, UK: Cambridge University Press, 1983.

McFadden, D. "The Measurement of Urban Travel Demand." Journal of Public Economics, Vol. 3 (1974), pp. 303328.

Miravete, E. "Choosing the Wrong Calling Plan? Ignorance and Learning.” American Economic Review, Vol. 93 (2002a), pp. 297-310.

—. "Estimating Demand for Local Telephone Service with Asymmetric Information and Optional Calling Plans." Review of Economic Studies, Vol. 69 (2002b), pp. 943-971.

Narayanan, S., Chintagunta, P., And Miravete, E. "The Role of Self Selection and Usage Uncertainty in the Demand for Local Telephone Service.” Quantitative Marketing and Economics, Vol. 5 (2007), pp. 1-34.

Nevo, A. "Measuring Market Power in the Ready-to-Eat Cereal Industry.” Econometrica, Vol. 69 (2001), pp. $307-342$.

Small, K. And Rosen, H. “Applied Welfare Economics with Discrete Choice Models.” Econometrica, Vol. 49 (1981), pp. $105-130$.

TAYLOR, L. And KRIDEL, D. "Residential Demand for Access to the Telephone Network.” In A. De Fontenay, M. Shugard, and D. SiBley, eds., Telecommunications Demand Modeling: An Integrated View. Amsterdam: North-Holland, 1990 . 
Telecommunications Research \& Action Center. “A Study of Telephone Competition in New York.” 2000.

_ . "Projected Residential Savings in California's Telephone Market." Available at: http://www.apt.org/publications/ reports-studies/apt-trac.pdf. (2001).

Train, K. Discrete Choice Methods with Simulation. Cambridge, UK: Cambridge University Press, 2002.

—, McFadden, D., AND Ben-AKiva, M. "The Demand for Local Telephone Service: A Fully Discrete Model of Residential Calling Patterns and Service Choices.” RAND Journal of Economics, Vol. 18 (1987), pp. 109-123.

Zolnierek, J., Eisner, J., and Burton, E. “An Empirical Examination of Entry Patterns in Local Telephone Markets." Journal of Regulatory Economics, Vol. 19 (2001), pp. 143-159. 